This item was submitted to Loughborough's Research Repository by the author.

Items in Figshare are protected by copyright, with all rights reserved, unless otherwise indicated.

\title{
Bunkering policies for a fuel bunker management problem for liner shipping networks
}

PLEASE CITE THE PUBLISHED VERSION

https://doi.org/10.1016/j.ejor.2019.07.044

PUBLISHER

Elsevier

VERSION

AM (Accepted Manuscript)

\section{PUBLISHER STATEMENT}

This paper was accepted for publication in the journal European Journal of Operational Research and the definitive published version is available at https://doi.org/10.1016/j.ejor.2019.07.044

LICENCE

CC BY-NC-ND 4.0

\section{REPOSITORY RECORD}

De, Arijit, Alok Choudhary, Metin Turkay, and Manoj Kumar Tiwari. 2019. "Bunkering Policies for a Fuel Bunker Management Problem for Liner Shipping Networks". Loughborough University.

https://hdl.handle.net/2134/9033818.v1. 


\section{Arijit De}

Newcastle University Business School, Newcastle University, Newcastle Upon Tyne, NE1 4SE, UK. Email: arijit.de@ncl.ac.uk

\section{Alok Choudhary (Corresponding Author)}

School of Business and Economics, Loughborough University, Leicestershire, LE113TU, UK Corresponding author's email: a.choudhary@lboro.ac.uk

\section{Metin Turkay}

Department of Industrial Engineering, Koc University, Rumelifeneri Yolu, 34450 Sariyer, Istanbul, Turkey

\section{Manoj K Tiwari}

Department of Industrial and Systems Engineering, Indian Institute of Technology, Kharagpur, Kharagpur -West Bengal 721302, INDIA 


\title{
Bunkering Policies for a Fuel Bunker Management Problem for Liner Shipping Networks
}

\begin{abstract}
This paper investigates the problem of bunker fuel management for liner shipping networks under different fuel pricing scenarios and taking into consideration different fuel bunkering policies. The fuel consumption of a vessel on a sailing leg may fluctuate as the real vessel speed deviates from the planned vessel speed. Furthermore, fluctuation of fuel prices at various ports increases the complexity of bunkering decisions related to the selection of the bunkering ports and the estimation of bunkered fuel cost.
\end{abstract}

We have developed a mixed integer non-linear programming model to minimise the total expected cost consisting of inventory cost related to container transportation, operating cost associated with ship hiring, as well as bunkering cost and fuel consumption cost at the port. The novelty of our research lies in its consideration of stochastic fuel consumption for different sailing legs, stochastic fuel prices at each port and different fuel bunkering policies to determine optimal bunker fuel management strategies for the selection of bunkering ports and for the estimation of the amount of bunkered fuel required.

We have proposed a novel approximate algorithm based on mathematical formulation and the fuel bunkering policies to calculate the total expected cost; the fuel inventory while arriving at and departing from the port; the number of vessels hired for weekly service; the arrival and departure time of the ship; and the amount of fuel bunkered at a port. We have performed extensive computational experiments on the practical routes to demonstrate the applicability, efficacy and robustness of the proposed novel methodology.

Keywords: Heuristics; Liner shipping; Bunker fuel management; Bunkering policies; Approximate algorithm

\section{Introduction}

The growing trend of dynamic bunker fuel prices affects liner shipping companies by increasing their overall operational costs, including the bunkering cost. The fluctuation of fuel prices, or the dynamic nature of bunker fuel prices at various ports complicates fuel bunkering decision related to the selection of bunkering ports and the estimation of the amount of bunkered fuel required. In 2011, the bunker fuel price at Singapore port reached $647 \mathrm{USD} /$ ton; thereby increasing the bunkering cost, while on $10^{\text {th }}$ March 2015, the bunker fuel price at Rotterdam port dropped significantly to $296 \mathrm{USD} /$ ton, which considerably cut the overall cost of shipping companies (Wang, 2016). The bunkering cost is significant for such companies as it constitutes approximately three- 
quarters of the total operating cost of a containership when the bunker fuel price is around 500 USD/ton (Ronen, 2011).

Furthermore, the fluctuation in vessel speed has a significant impact on fuel consumption as increasing the vessel speed leads to increased fuel consumption and more bunkering of fuel at the ports. Liner shipping companies employ a slow steaming strategy to reduce the speed of their vessels to lower the fuel consumption and to counter any rise in bunker fuel prices. Meanwhile, decreasing the vessel speed leads to an increase in the travel time, and thereby companies need to deploy more vessels to perform the weekly service of the shipping company on a specific route, leading to an increase in the capital cost, labour costs, and etc. Nevertheless, the savings obtained from reduced bunker fuel cost has the potential to outweigh the increase in other costs due to the addition of more number of vessels for the weekly service (Ronen, 2011).

Bunker fuel management is essential to optimize the sailing speed by maintaining an ideal trade-off between fuel consumption on a specific sailing leg and the amount of fuel bunkered at subsequent ports. Therefore, it is essential for liner shipping companies to investigate bunker fuel management under different fuel pricing scenarios, as the fluctuating fuel prices and varying vessel speed influence bunkering decisions. Ideally, if the fuel prices for different ports have been predicted accurately, then it becomes easier to minimize the total fuel cost. However, the fluctuations of the bunker fuel price and fuel consumption for each sailing leg make it imperative to adopt appropriate bunkering policies to reduce the bunkering cost.

The slow steaming strategy is favourable in terms of mitigating fuel consumption and lowering greenhouse gas emissions. However, reducing the vessel speed will increase the sailing time and will lead the vessel to fail to reach a port by the expected arrival time. Late arrival at a port results in the deviation from the planned schedule and causes delays at subsequent ports of calls. Early arrival, meanwhile, leads to port congestion and may incur penalty charges (De et al., 2017). Some researchers have considered time-window range and penalizing strategies in their research to manage delay in finishing the port operations and thereby improving the service level of the ports ((Agra et al., (2013), Hemmati et al., (2016), and De et al., (2016)). The variability in port times is a serious problem as it causes substantial delays and ultimately in a poor service level (Aydin et al., (2017) and De et al., (2018)). In certain cases, such as an unforeseen delay at a port, a vessel may not reach its next port of call within the expected arrival time even if its management decide to sail at maximum speed. Hence, it is imperative for the liner shipping companies to consider uncertain port times while determining vessel speed to meet the planned schedule and mitigate poor service level.

This paper investigates fuel bunker management problem to determine the bunkering ports and bunkering amounts under different fuel pricing scenarios while considering different bunker fuel policies. We integrate slow steaming policy to depict the real vessel speed, which varies within a 
specific range of the planned speed. The total number of vessels deployed to maintain the weekly service frequency is determined by considering the uncertain port times of the vessel and sailing times between ports of call. Likewise, arrival time and departure time of a vessel at various ports are estimated by considering uncertain port times and sailing times between ports of call.

We have presented a mathematical model with the objective of minimizing the total expected cost comprising inventory cost while sailing on the route, bunkering cost, fuel consumption cost at ports, a fixed cost associated with hiring vessels, penalty cost for waiting before starting its operation, and demurrage costs for delay in finishing port operations. We have taken into consideration various fuel bunkering policies for bunker fuel price at different ports, fuel consumption on sailing legs, as well as the fuel inventory of the vessel while arriving at the port. Moreover, we have proposed a novel approximate algorithm considering mathematical formulation and different fuel bunkering policies. The real-world liner shipping network Asia-Europe-Oceania network and Atlantic Pacific Express service route have been selected to validate the proposed mathematical model and the approximate algorithm.

This paper is organised as follows: section 2 presents a literature review on slow steaming strategy and bunker fuel management, highlighting specific research gaps before also highlighting the contribution of this paper; section 3 discusses the problem description and the formulation of the mathematical model; section 4 provides various fuel bunkering policies which should be taken into consideration account while carrying out fuel bunkering; section 5 presents the proposed solution methodology; section 6 discusses the extensive computational experiments performed for the validation of our research; and section 7 concludes this research and outlines the scope for future research.

\section{Literature Review}

This section provides a literature review covering areas including slow steaming strategy and bunker fuel management to identify existing research gaps and methodological challenges.

\subsection{Slow Steaming Strategy}

There are several studies to have incorporated slow steaming strategy to determine the optimal vessel speed on a route considering different sailing legs ((Notteboom et al., 2009) and (Ronen, 2011)). Some studies have considered the speed optimization problem within a liner shipping network and incorporated the time-window concept to improve the service level of a port ((Fagerholt et al., (2010) and Hvattum et al., (2013)). Meanwhile, other researchers have employed ship speed optimization to estimate the fuel consumption of a vessel while sailing on different sailing legs of a route (Yao et al., (2012) and Ghosh et al., (2015)). Slow steaming reduces fuel consumption but may also lead to more container ships being required to perform the weekly service frequency (Wang et al., (2012b)). Shipping companies opt for a slow steaming policy to lower the bunker cost in two 
circumstances: when the fuel price is extremely high; and when a large number of container vessels are in lay-up. Vernimmen et al., (2007) presented an example of two international shipping companies - Grand Alliance and CMA CGM - with each deciding to add a ninth vessel to their respective AsiaEurope route to cope with the rise of bunker fuel price by opting for a slow steaming policy. The bunkering fuel cost saved by the other eight vessels was found to be much higher when compared with the cost of hiring and operating the ninth vessel. Some of the studies to have dealt with vessel speed optimization problems aimed to determine the number of ships deployed on the weekly service and then estimate the optimal vessel speed to reduce fuel consumption while maintaining the service level (Wang et al., 2016). Wang et al., (2016) also discussed several trade-offs necessary when solving a sailing speed optimization problem. As the shipping companies have a limited number of container vessels, if one service employs too many ships, then other services may fall short. Removing a vessel from an existing service will lead to an increase in speed for the remaining ships to maintain weekly service frequency which, in turn will increase the fuel consumption rate. By utilizing more vessels on shipping lines, fuel consumption can be lowered but deploying additional vessels will increase the cost of chartering. Adopting a low sailing speed saves fuel consumption but leads to longer travel time for vessel, which, in turn, increases the inventory cost of the containers. Hence, sailing a vessel at a slower speed might not be favourable from the customer's point of view.

Higher vessel speed increases fuel consumption and reduces transit time (Wang, 2016). Container shipping companies aim to determine the optimal vessel speed, so that an optimal trade-off can be maintained between fuel cost, transit time and shipping cost associated with the number of vessels deployed on the shipping service. Some researchers have mentioned that lowering the sailing speed to control the fuel consumption in the case of high bunker prices will lead to longer inter-arrival times between two ports of call and longer round-trip times (Wang et al., (2012a)). In such cases, more vessels need to be deployed to efficiently perform the weekly service and meet customer demand within a specified time. Some research has considered uncertainties at sea and at ports while estimating the optimal sailing speed for each voyage leg, and minimized the bunker cost while maintaining a required sailing time between two consecutive ports of call (Wang et al., (2012a)).

The majority of the research presented above has considered a slow steaming policy with the aim to minimize fuel consumption and thereby fuel cost. However, employing slow steaming or reducing the vessel speed will increase the sailing time and results in more vessels having to be deployed to honour the shipping company's weekly service and port demands. Bunker fuel management helps in maintaining an ideal trade-off between vessel speed, fuel consumption at different sailing legs, and fuel bunkering at ports. Moreover, bunker fuel management also plays a significant role in reducing the fuel cost, as it strategically determines the possible bunkering ports based on dynamic fuel prices at different ports and estimates the fuel bunkering amounts. Therefore, it is imperative to consider the relationships between slow steaming, travelling time and number of 
vessels to be deployed when making fuel bunkering decisions (i.e. where to bunker and how much to bunker). The next section provides a critical review of the relevant literature on bunker fuel management.

\subsection{Bunker Fuel Management}

The literature related to bunker fuel management is limited and little research has been devoted to the selection of bunkering ports and the estimation of bunkering amounts. Kim et al., (2012) determined the optimal sailing speed and amount of fuel required for each vessel route and identified possible bunkering ports where refuelling could be performed. The study compared the amount of fuel consumed and the number of bunkering ports required while employing a slow steaming policy and while sailing at normal speeds.

Yao et al., (2012) discussed the problem of bunker fuel management for a liner shipping service of the following three components (which needed to be jointly optimized); the selection of bunkering ports; the estimation of the bunkering amounts; and the adjustment of vessel speed on different sailing legs. Their model did not consider the uncertainties associated with the fluctuation of bunker fuel prices and the variation in fuel consumption on different sailing legs. Some of the other limitations of their model related to limiting the number of bunkering times and assuming that the vessel would arrive within a pre-defined time-window. H. J. Kim, (2014) overcame some of these limitations by presenting a bunkering model where a ship can arrive at anytime at ports. Their model aimed to minimize the total bunkering cost, the chartering cost of the vessel, and the time value related to each container. Sheng, Lee, \& Chew, (2014) extended the research of Yao et al., (2012) by considering the fluctuating nature of the fuel prices and addressed the uncertainties of fuel consumption. The amount of fuel consumed while sailing determines the possible bunkering ports and the amount of fuel to be bunkered. The selection of bunkering ports, discussed by Sheng et al., (2014) is not very sensitive to the changes in bunker fuel price, and this hitherto scarcely researched issue is addressed in this paper.

Meng et al., (2015) studied fuel price fluctuation and depicted that a price difference of 200 USD/ton can lead to a daily cost of 6,000 USD if the daily bunker consumption is 30 tons. The fluctuating bunker fuel price was considered by Meng et al., (2015), however, they neglected other practical aspects such as the variability associated with sailing time, the port operation time, and the need to consider fuel bunkering policies while dealing with dynamic fuel prices. Another limitation of Meng et al., (2015) was associated with the assumption that a vessel would sail at a constant speed on a voyage leg. Zhen et al., (2017) presented a threshold-based policy for the performance of fuel bunkering, and their research had some potential for extension to consider several fuel bunkering policies while considering the dynamic fuel prices at different ports. The proposed research considered these limitations and took into account the fluctuating fuel prices at different ports and 
accordingly determines the bunkering policies related to the selection of bunkering ports and bunkering amounts.

The proposed research also addressed the challenge of considering the variability associated with vessel speed as stated by De et al., (2019b). Wang et al., (2015) dealt with the refuelling of the bunker on a vessel while considering that the real speed of the vessel may deviate from the planned speed. Their study addressed the variability of the sailing speed in reality and assumed that the real speed of the vessel might vary within a given range while sailing between two ports. However, their research neglected the role of fluctuating fuel prices at different ports in the decision-making process. The novelty of our research lies in addressing these limitations of existing research and considering the variability of vessel speed within our mathematical model.

A few other studies have considered the variability of fuel price at different ports and varying fuel consumption in each sailing leg while determining the bunkering ports and bunkering amounts (Zhen et al., 2017). Such studies also overlooked the need to integrate certain practical aspects such as the relationship between vessel speed and port arrival times, as well as uncertain port operational times. The port service time variability was addressed while dealing with a speed optimization problem by Aydin et al., (2017) with the aim of determining the optimal vessel speed, bunkering ports and bunkering amounts. Nevertheless, the latter research did overlook fluctuation of vessel speed on a sailing leg, a research issue which is addressed in this paper.

\subsection{Objectives and Contribution}

This paper addresses a practical problem associated with speed optimization and bunker fuel management under different fuel pricing scenarios. In practice, the real speed of a vessel keeps changing within a given range above and below the planned speed. Thus, we do take into consideration variation in real speed in this study to address the uncertainties related to fuel consumption on a given sailing leg. The majority of earlier studies such as Yao et al., (2012), Wang et al., (2012b), Meng et al., (2015) and Aydin et al., (2017) considered the bunker prices to be a deterministic parameter, although in reality bunker fuel prices are stochastic in nature, and hence, fuel bunkering policies need to take dynamic fuel prices into consideration. The proposed research focuses on a bunker fuel management problem while considering the dynamic nature of bunker fuel price and fluctuation in fuel consumption for each sailing leg. We propose a fuel bunkering policy for vessels that takes into account the uncertainties associated with fuel consumption, variation in vessel speed, and fluctuating bunker fuel prices at various ports. We regulate the vessel speed to minimize bunker fuel consumption and estimate the number of vessels to be deployed on a route to carry out the weekly service. Fuel bunkering policies help in the selection of bunkering ports and in determining the amount of fuel bunkered at each refill ports while taking into account the fluctuating fuel prices. Strategic bunkering decisions based on carefully considered fuel bunkering policies help to lower the 
overall bunkering cost. We consider the time-window range to enhance the service level at a port by penalizing vessels for waiting time before starting its port operations. The penalty costs is considered to counter the time-window violation associated with the vessel failing to finish its operations within the time-window range.

\section{Problem Description}

A liner container shipping company operates its vessels on several routes and serves multiple ports to meet container demands. Each ship route comprises of a number of ports of call and the port rotation can be represented in the following way.

$q_{r 1} \rightarrow q_{r 2} \rightarrow \cdots \rightarrow q_{r P_{r}} \rightarrow q_{r 1}$

Here, the ship route represented as $r$ belongs to a set of routes $R$ and $q_{r j}$ is the $j^{\text {th }}$ port of call associated with route $r$. The number of port of calls on a specific vessel route $r \in R$ is $P_{r}$, and the set of port calling indices for ship route $r \in R$ can be depicted as $\lambda_{r}$; where $\lambda_{r}=\left\{1,2, \ldots P_{r}\right\}$. The following discusses the notations used in this study.

\section{Indices}

$r: \quad$ Routes

$j: \quad$ Port of call

$p: \quad$ Bunker price scenario

\section{Sets}

$R: \quad$ Set of ship routes

$\lambda_{r}$ : $\quad$ Port of calls on vessel route $r$

$P$ : $\quad$ Set of bunker fuel price scenarios

\section{Parameters}

$\alpha: \quad$ Inventory cost for each containers (USD per TEU per hour)

$t_{r j}^{\text {port }}$ : Time spent by the ship at the $j^{\text {th }}$ port of call for vessel route $r \in R$

$D_{r j}$ : Distance of the leg started from $j^{\text {th }}$ port of call of vessel route $r \in R$

$V_{r j}$ : Number of containers (TEUs) transported on the leg started from $j^{\text {th }}$ port of call of vessel route $r \in R$

$U_{r}: \quad$ Vessel's bunker tank capacity travelling on route $r \in R$

$\xi^{p}: \quad$ Probability of the occurrence of price scenario $p$

$C_{r}^{\text {ship }}:$ Fixed cost related to the ship's operation on route $r \in R$

$s_{r}^{\max }:$ The maximum vessel speed (knot) on route $r \in R$

$s^{e r r}:$ Variability associated with the real sailing speed

$\underline{\mu_{r j}}, \overline{\mu_{r j}}: \quad$ Time window range at $j^{\text {th }}$ port of call of route $r \in R$ 
$\theta_{r j}$ : Penalty cost per hour for the delay in finishing port operations at $j^{\text {th }}$ port of call of route $r \in R$

$\phi_{r j}: \quad$ Waiting cost per hour at $j^{\text {th }}$ port of call of route $r \in R$

$k^{p}: \quad$ Average amount of fuel (marine diesel oil) consumed at the port per hour under scenario $p \in P$

$h_{r j}^{p}$ : Price of fuel (marine diesel oil) consumed at $j^{\text {th }}$ port of call of route $r \in R$ under scenario $p \in P$

$F_{r j}^{p}$ : Fixed cost for carrying out bunkering at $j^{\text {th }}$ port of call of route $r \in R$ under scenario $p \in P$

$\eta_{r j}^{p}$ : $\quad$ Bunkering price per ton of heavy fuel oil at $j^{\text {th }}$ port of call of route $r \in R$ under scenario $p \in P$

\section{Continuous and Integer Variables}

$\bar{x}_{r j}$ : $\quad$ Bunker fuel (tons) in the vessel's bunker tank while arriving at the $j^{\text {th }}$ port of call of route $r \in R$ under scenario $p \in P$

$x_{r j}^{p}$ : Bunker fuel (tons) in the vessel's bunker tank while departing from the $j^{\text {th }}$ port of call of route $r \in R$ under scenario $p \in P$

$n_{r}^{p}: \quad$ Number of vessels deployed on route $r \in R$ under scenario $p \in P$

$s_{r j}$ : $\quad$ Planned vessel speed on the leg starting from the $j^{\text {th }}$ port of call of route $r \in R$ under scenario $p \in P$

$y_{r j}^{p}$ : Bunker fuel loaded on vessel at $j^{\text {th }}$ port of call of route $r \in R$ under scenario $p \in P$

$t_{r j p}^{a r r}$ : Arrival time at $j^{\text {th }}$ port of call associated with route $r \in R$ under scenario $p \in P$

$t_{r j p}^{d e p}:$ Departure time at $j^{\text {th }}$ port of call associated with route $r \in R$ under scenario $p \in P$

\section{Binary Variables}

$z_{r j}^{p} \quad=1$, if fuel bunkering is performed at the $j^{\text {th }}$ port of call of route $r \in R$ under scenario $p \in P$ and 0 , otherwise. $z_{r j}^{p} \in\{0,1\}$

\subsection{Weekly service, ship operating cost and inventory cost}

For maintaining the weekly service frequency, homogeneous vessels are deployed on each vessel route. The liner shipping company maintains a weekly service frequency and operates the vessels for 168 hours (i.e. total hours in a week). Hence, the total time required by the fleet of vessels to complete a weekly service frequency is $168 \times n_{r}^{p}$ hours. For maintaining the weekly service frequency, the following relationship holds true. This is also supported by Wang et al., (2015).

$$
\sum_{j \in \lambda_{r}}\left(\frac{D_{r j}}{s_{r j}}+t_{r j}^{p o r t}\right)=168 \times n_{r}^{p}, \quad \forall r \in R, \forall p \in P
$$


Here, $\left(\frac{D_{r j}}{\frac{-p}{s_{r j}}}\right)$ (hour) represents sailing time on the leg starting from $j^{\text {th }}$ port of call in route $r \in R$ under bunker fuel scenario $p \in P$. The fixed cost for operating vessels on all the routes for a certain price scenario is given by, $\sum_{r \in R} C_{r}^{s h i p} n_{r}^{p}$. Now, a higher sailing speed of the vessel leads to a lower inventory cost, which can be represented as, $\sum_{r \in R} \sum_{j \in \lambda_{r}} \alpha V_{r j} \frac{D_{r j}}{S_{r j}}$ for a particular fuel price scenario $p \in P$.

\subsection{Vessel arrival and departure time and random port time}

$t_{r j p}^{a r r}$ is the arrival time at the $j^{\text {th }}$ port of call associated with route $r$ for a price scenario $p$, hence the relationship between travelling time $\left(\frac{D_{r j}}{\frac{-p}{s_{r j}}}\right)$ and arrival time can be expressed in the following way,

$$
t_{r j p}^{a r r}+t_{r j}^{p o r t}+\frac{D_{r j}}{-p}=t_{r(j+1) p}^{a r r}, \quad \forall r \in R, \forall j \in \lambda_{r}, \forall p \in P
$$

The departure time of the vessel can be represented in terms of arrival time, time window range and service time,

$$
t_{r j p}^{d e p}=t_{r j p}^{\text {port }}+\max \left\{t_{r j p}^{a r r}, \underline{\mu_{r j}}\right\}, \quad \forall r \in R, j \in \lambda_{r}
$$

The time spent by a vessel at a port depends on several factors such as number of quay cranes allocated to the ship, the number of containers to be loaded and unloaded, and the efficiency of the quay crane operators etc. The values pertaining to these factors fluctuates, hence the port time for a vessel cannot be predicted at the stage of ship route design. For addressing this issue, the parameter $t_{r j}^{\text {port }}$ depicting the time spent by a vessel at a port is generated by considering a predetermined probability distribution function $f\left(t_{r j}^{\text {port }}\right)$ defined on an interval $\left[\overline{t_{r j}^{\text {port }}}, \underline{t_{r j}^{p o r t}}\right]$, where $\overline{t_{r j}^{\text {port }}}$ and $\underline{t_{r j}^{p o r t}}$ are non-negative parameters.

\subsection{Bunker consumption, bunkered amount and fuel cost}

The vessel speed is influenced by the weather condition of the sea and changes made by the captain while sailing in the sea and hence the vessel speed cannot remain constant over a voyage leg. The vessel speed in practicality keeps changing with time $t$ on a leg starting from $j^{\text {th }}$ port of call of route $r \in R$ under fuel price scenario $p \in P$ and can be denoted by $s_{r j}^{p}(t)$. The range of the vessel speed in reality can be expressed in the following way, 
$s_{r j}^{-p}-s^{e r r} \leq s_{r j}^{p}(t) \leq s_{r j}^{-p}+s^{e r r}$,

The vessel runs on heavy fuel oil (HFO) while sailing in sea and the price of heavy fuel oil (HFO) is much lower than marine diesel oil (MDO) which is used by the vessel while operating at a port (De et al., 2016). Therefore, total fuel cost incurred per hour at $j^{\text {th }}$ port of call of route $r \in R$ under scenario $p \in P$ can be expressed as, $\varphi_{r j}^{p}=h_{r j}^{p} k^{p}$.

The bunker consumption (tons per hour) function associated with heavy fuel oil (HFO) is proportional to the power function of the vessel speed as mentioned in several studies ((Ronen, 2011) and (Wang et al., 2012b)).Hence, bunker consumption can be represented as,

$$
B_{r j}(s)=a_{r j} s^{b_{r j}}, \quad a_{r j}>0, b_{r j}>2
$$

Here, $B_{r j}(s)$ is the bunker consumption function with respect to speed $s$ on a sailing leg starting from $j^{\text {th }}$ port of call of route $r$. As the vessel speed is adjusted by the ship captain from time to time for dealing with weather related adversities, hence the real bunker fuel consumption keeps changing throughout the voyage time of a ship on a specific leg. In practicality, the bunker fuel consumption on a leg starting from $j^{t h}$ port of call of route $r \in R$ is expressed as $G_{r j}\left(s_{r j}^{p}(t)\right)$ and it depends on the varying vessel speed $s_{r j}^{p}(t)$. The bunker fuel consumption could be computed using the following equation (Wang \& Meng, 2015).

$$
G_{r j}\left(s_{r j}^{p}(t)\right)=\int_{0}^{D_{r j} / s_{r j}} B_{r j}\left(s_{r j}^{p}(t)\right) d t,
$$

The maximum possible bunker consumption associated with real bunker consumption function $G_{r j}\left(s_{r j}^{p}(t)\right)$ is denoted by $G_{r j}^{\max }\left(s_{r j}^{p}\right)$. The bunkering services are provided to the vessel on certain ports and the amount of bunker loaded at a port for a certain route can be computed in the following way, $y_{r j}^{p}=\left(\bar{x}_{r j}^{p}-\underline{x}_{r j}^{p}\right) z_{r j}^{p}$. The bunker cost, $C_{r j p}^{b u n}$ is related to the bunkering price per ton of fuel, $\eta_{r j}^{p}$ and it can be represented in the following way,

$C_{r j p}^{b u n}=\eta_{r j}^{p} y_{r j}^{p}$,

Total bunkering cost for each scenario can be computed as $\sum_{r \in R} \sum_{j \in \lambda_{r}} C_{r j p}^{b u n}$.

\subsection{Worst case bunker consumption model}

Before developing the mathematical model, it is essential to provide a model for computing the bunker consumption on a sailing leg for the worst-case condition considering the fuel pricing 
scenarios. The worst case bunker fuel consumption for a particular sailing leg of a route can be estimated using the following model given by Wang \& Meng (2015).

$$
\left.G_{r j}^{\max }\left(\bar{s}_{r j}^{p}\right)=\max _{s_{r j}^{p}(t)}^{D_{r j} / \bar{s}_{r j}^{p}} \int_{0}^{p_{r j}} B_{r j}(t)\right) d t,
$$

Equation (8) is one of the constraints depicting the arrival of the vessel at the next port visit as par the planned schedule. The variability of the vessel speed is given by the equation (9).

$$
\begin{aligned}
& \int_{0}^{D_{r j} / s_{r j}^{p}} s_{r j}^{p}(t) d t=D_{r j}, \\
& \bar{s}_{r j}^{p}-s^{e r r} \leq s_{r j}^{p}(t) \leq \bar{s}_{r j}+s^{e r r},
\end{aligned}
$$

The value of $s^{\text {err }}$ is assumed to be small and the higher value of $s_{r j}$ may lead to significant consumption of bunker fuel and lower value of ${ }^{-p}$. leads to deploying of large number of vessels; thereby increasing the hiring cost.

\subsection{Bunker fuel management model}

Wang et al., 2015 obtained a close-form expression for $G_{r j}^{\max }\left(\bar{s}_{r j}^{p}\right)$ after solving the worst case bunker consumption model. So, referring to Wang \& Meng, 2015, $G_{r j}^{\max }\left(\vec{s}_{r j}\right)$ can be computed using equation (10).

$G_{r j}^{\max }\left(\bar{s}_{r j}^{p}\right)=\frac{a_{r j} D_{r j}}{2 s_{r j}^{-p}}\left[\left(\bar{s}_{r j}^{p}+s^{e r r}\right)^{b_{r j}}+\left(\bar{s}_{r j}-s^{e r r}\right)^{b_{r j}}\right]$,

The objective function of the bunker fuel management model can be represented as follows

\section{Minimize}

$$
\left.\sum_{p \in P} \xi^{p}\left(\begin{array}{l}
\sum_{r \in R} \sum_{j \in \lambda_{r}} \alpha V_{r j} \frac{D_{r j}}{-p}+\sum_{r \in R} \sum_{j \in \lambda_{r}} C_{r j p}^{b u n}+\sum_{r \in R} \sum_{j \in \lambda_{r}} \varphi_{r j}^{p}\left(t_{r j}^{d e p}-t_{r j}^{a r r}\right)+\sum_{r \in R} C_{r}^{s h i p} n_{r}^{p} \\
+\sum_{r \in R} \sum_{j \in \lambda_{r}} \phi_{r j}\left[\underline{\mu_{r j}}-t_{r j p}^{a r r}\right]^{+}+\sum_{r \in R} \sum_{j \in \lambda_{r}} \theta_{r j}\left[t_{r j p}^{d e p}-\overline{\mu_{r j}}\right]^{+}
\end{array}\right)\right\}
$$

The objective function (11) minimizes the total expected cost comprising of the inventory cost while sailing on different legs, cost associated with the bunkering of heavy fuel oil, cost related to the consumption of marine diesel oil at the port, fixed cost for deploying vessels on all the routes, waiting cost for arriving before the starting of the time window range and penalty charges for 
finishing the port operations outside the time window. Here, $\left[\underline{\mu_{r j}}-t_{r j p}^{a r r}\right]^{+}=\max \left\{\underline{\mu_{r j}}-t_{r j p}^{a r r}, 0\right\}$ and $\left[t_{r j p}^{d e p}-\overline{\mu_{r j}}\right]^{+}=\max \left\{t_{r j p}^{d e p}-\overline{\mu_{r j}}, 0\right\}$. Constraints of the mathematical model are presented as follows, $\sum_{j \in \lambda_{r}}\left(\frac{D_{r j}}{-p}+t_{r j}^{p o r t}\right)=168 \times n_{r}^{p} ; \quad \forall r \in R, \forall p \in P$

$\underline{x}_{r j}^{p} \geq 0, \bar{x}_{r j}^{p} \geq 0 ;$

$\forall r \in R, \forall j \in \lambda_{r}, \forall p \in P$

$\bar{x}_{r j}^{p}-\underline{x}_{r j}^{p} \leq U_{r} z_{r j}^{p}$

$\forall r \in R, \forall j \in \lambda_{r}, \forall p \in P$

$\underline{x}_{r j}^{p}-\bar{x}_{r(j+1)}^{p} \leq G_{r j}^{\max }\left(\bar{s}_{r j}\right)$;

$\forall r \in R, \forall j \in \lambda_{r}, \forall p \in P$

$y_{r j}^{p}=\left(\bar{x}_{r j}^{p}-\underline{x}_{r j}^{p}\right) z_{r j}^{p}$

$\forall r \in R, \forall j \in \lambda_{r}, \forall p \in P$

Constraint (12) depicts the weekly service frequency conducted by the vessels on a certain route for a specific bunker fuel price scenario. This constraint includes a fractional term that makes the model nonlinear. Equation (13) presents the non-negativity constraints for the amount of bunker fuel on the vessel while arriving and leaving the port. If the fuel bunkering takes place at a port, then constraint (14) ensures that the amount of fuel bunkered at a vessel must be less than or equal to the bunker tank capacity of the vessel. Constraint (15) provides the relationship of bunker consumption on a certain leg with the bunker capacity of the vessel while leaving a port and bunker capacity while arriving at the next port. Constraint (16) provides the amount of fuel bunkered at a port includes multiplication of binary variable with continuous variable.

$$
\begin{array}{ll}
t_{r j p}^{a r r}+t_{r j}^{p o r t}+\frac{D_{r j}}{s_{r j}}=t_{r(j+1) p}^{a r r} ; & \forall r \in R, \forall j \in \lambda_{r}, \forall p \in P \\
t_{r j p}^{d e p}=t_{r j}^{p o r t}+\max \left\{t_{r j p}^{a r r}, \underline{\left.\mu_{r j}\right\}} ;\right. & \forall r \in R, \forall j \in \lambda_{r}, \forall p \in P
\end{array}
$$

Constraint (17) presents the relationship between the arrival time, service time and travel time from one port to another. Constraint (18) determines the departure time of the vessel on a certain port of the route by considering the service time at the port and vessel's arrival time under certain bunker fuel pricing scenario.

$$
\begin{array}{ll}
\bar{x}_{r j}^{p}, \underline{x}_{r j}^{p}, y_{r j}^{p} \geq 0 ; & \forall r \in R, \forall j \in \lambda_{r}, \forall p \in P \\
n_{r}^{p} \geq 0 ; & \forall r \in R, \forall p \in P \\
\bar{s}_{r j} \geq 0 ; & \forall r \in R, \forall j \in \lambda_{r}, \forall p \in P
\end{array}
$$




$$
\begin{array}{ll}
t_{r j p}^{a r r}, t_{r j p}^{d e p} \geq 0 ; & \forall r \in R, \forall j \in \lambda_{r}, \forall p \in P \\
z_{r j}^{p} \in\{0,1\} ; & \forall r \in R, \forall j \in \lambda_{r}, \forall p \in P
\end{array}
$$

Equations (19) and (20) are the integer variables, equations (21) and (22) represent the continuous variables and equation (23) is the binary variable. The next section provides the fuel bunkering policies adopted for determining the bunkering ports and bunkering amount while considering the fluctuating fuel prices at different ports.

\section{Fuel bunkering policy}

Some of properties related to the fuel bunkering policy are mentioned in this section. Fuel bunkered at $j^{\text {th }}$ port of call in a route $r \in R$ under scenario $p \in P$ is represented as $y_{r j}^{p}$.

Proposition 1. Fuel bunkering policy at $\left(P_{r}-1\right)^{t h}$ port of call of route $r \in R$ is given by

$$
\begin{aligned}
& y_{r\left(P_{r}-1\right)}^{p}=\left\{\begin{array}{cl}
0, & G_{r\left(P_{r}-1\right)}^{\max }\left(\bar{s}_{r\left(P_{r}-1\right)}^{p}\right) \leq \bar{x}_{r\left(P_{r}-1\right)} \\
G_{r\left(P_{r}-1\right)}^{\max }\left(\bar{s}_{r\left(P_{r}-1\right)}^{p}\right)-\bar{x}_{r\left(P_{r}-1\right)}^{p}, & G_{r\left(P_{r}-1\right)}^{\max }\left(\bar{s}_{r\left(P_{r}-1\right)}\right)>\bar{x}_{r\left(P_{r}-1\right)}^{p}
\end{array}\right. \\
& \text { Hence, } z_{r\left(P_{r}-1\right)}^{p}=\left\{\begin{array}{l}
0, G_{r\left(P_{r}-1\right)}^{\max }\left(s_{r\left(P_{r}-1\right)}^{p}\right) \leq \bar{x}_{r\left(P_{r}-1\right)}^{p} \\
1, G_{r\left(P_{r}-1\right)}^{\max }\left(\bar{s}_{r\left(P_{r}-1\right)}^{p}\right)>\bar{x}_{r\left(P_{r}-1\right)}^{p}
\end{array}\right.
\end{aligned}
$$

Where $P_{r}$ is the number of ports associated with a route $r \in R$ and $\left(P_{r}-1\right)^{t h}$ port is the second last port of call of route $r \in R$.

In words, the vessel performs fuel bunkering at the second last port of call $\left(P_{r}-1\right)^{\text {th }}$, only if the amount of fuel on the vessel while arriving at the second last port is less than the maximum amount of fuel consumed while sailing from second last port of call $\left(P_{r}-1\right)^{\text {th }}$ to last port of call $P_{r}^{\text {th }}$

Proof. As the last leg comprises of $\left(P_{r}-1\right)^{\text {th }}$ and $P_{r}^{\text {th }}$ port, hence the vessel doesn't need to perform bunkering $\left(\right.$ or, $\left.z_{r\left(P_{r}-1\right)}^{p}=0\right)$ at $\left(P_{r}-1\right)^{\text {th }}$ port if the remaining fuel on the vessel while arriving at $\left(P_{r}-1\right)^{\text {th }}$ port is enough for sailing on the last leg from $\left(P_{r}-1\right)^{\text {th }}$ port to $P_{r}^{\text {th }}$ port (or, $\left.G_{r\left(P_{r}-1\right)}^{\max }\left(s_{r\left(P_{r}-1\right)}^{-p}\right) \leq \bar{x}_{r\left(P_{r}-1\right)}^{p}\right)$. Although, the vessel performs bunkering $\left(\right.$ or, $\left.z_{r\left(P_{r}-1\right)}^{p}=1\right)$ at 
$\left(P_{r}-1\right)^{t h}$ port only if the maximum fuel consumption on the last sailing leg is more than the fuel remaining on the vessel when it arrives at $\left(P_{r}-1\right)^{t h}$ port $\left(\right.$ or, $\left.G_{r\left(P_{r}-1\right)}^{\max }\left(\bar{s}_{r\left(P_{r}-1\right)}^{p}\right)>\bar{x}_{r\left(P_{r}-1\right)}\right)$ and the bunkered amount is equivalent to $G_{r\left(P_{r}-1\right)}^{\max }\left(\bar{s}_{r\left(P_{r}-1\right)}^{p}\right)-\bar{x}_{r\left(P_{r}-1\right)}^{p}$. The aforementioned description completes the proof for Proposition 1.

Proposition 2. When the fuel price at a port is higher than the price at the next port or $\eta_{r j}^{p}>\eta_{r(j+1)}^{p}$ and the fuel remaining on the vessel while arriving at the port is less than maximum fuel consumption for the next leg or $G_{r j}^{\max }\left(\bar{s}_{r j}\right)>\bar{x}_{r j}$, then the vessel will perform bunkering at $j^{\text {th }}$ port of call of route $r \in R$ up to the level of maximum fuel consumption for the next leg or $G_{r j}^{\max }\left(\bar{s}_{r j}\right)$.

So, if $\eta_{r j}^{p}>\eta_{r(j+1)}^{p}$, then $y_{r j}^{p}=\left\{\begin{array}{cc}0, & G_{r j}^{\max }\left(s_{r j}^{p}\right) \leq \bar{x}_{r j}^{p} \\ G_{r j}^{\max }\left(s_{r j}^{p}\right)-\bar{x}_{r j}, & G_{r j}^{\max }\left(\bar{s}_{r j}\right)>\bar{x}_{r j}^{p}\end{array}\right.$

Proof. If the fuel price on $j^{\text {th }}$ port of call is more than $(j+1)^{t h}$ port of call of route $r \in R$ (or, $\left.\eta_{r j}^{p}>\eta_{r(j+1)}^{p}\right)$, then the general tendency is to not perform fuel bunkering at $j^{\text {th }}$ port of call (or, $\left.z_{r j}^{p}=0\right)$ and thereby, helping the objective of minimizing the overall bunkering cost. Moreover in such a scenario $\left(\right.$ or, $\left.\eta_{r j}^{p}>\eta_{r(j+1)}^{p}\right)$, if the maximum fuel required for sailing from $j^{\text {th }}$ port of call to the $(j+1)^{t h}$ port of call of route $r \in R$ is less than the available fuel on the vessel after arriving at $j^{\text {th }}$ port of call $\left(\right.$ or, $\left.G_{r j}^{\max }\left(\bar{s}_{r j}\right) \leq \bar{x}_{r j}\right)$, then the vessel doesn't perform bunkering at $j^{\text {th }}$ port of call (or, $\left.z_{r j}^{p}=0\right)$ and the hence the bunkered amount is zero (or, $\left.y_{r j}^{p}=0\right)$. Although, if the remaining fuel on the vessel after arriving at $j^{\text {th }}$ port of call is less than maximum fuel consumption for the sailing leg starting from $j^{\text {th }}$ port of call $\left(\right.$ or, $\left.G_{r j}^{\max }\left(\bar{s}_{r j}^{p}\right)>\bar{x}_{r j}\right)$, then the vessel has to perform the bunkering at $j^{\text {th }}$ port of call $\left(\right.$ or, $\left.z_{r j}^{p}=1\right)$ and yet ensure that the bunkering cost stays as less as possible. Hence, in such a scenario the maximum amount of fuel bunkered at $j^{\text {th }}$ port of call is equivalent to $y_{r j}^{p}=G_{r j}^{\max }\left(\begin{array}{c}-p \\ s_{r j}\end{array}\right)-\overline{x_{r j}}$. 
Assumption 1. For a certain fuel price at a port, the vessel performs the fuel bunkering when the amount of fuel in the tank is less than a specific threshold level.

(Zhen et al., 2017) used a threshold based policy to carry out the fuel bunkering and accordingly the assumption 1 is justified. Although, the threshold based policy can be considered for performing bunkering only when the fuel price at a port is reasonable.

Proposition 3. The fuel bunkering policy is a threshold-based strategy and depends upon the bunker fuel price at a port under a certain scenario, $\eta_{r j}^{p}$. The threshold function is taken into consideration when the fuel price at a port is less than the price at the next port, $\eta_{r j}^{p} \leq \eta_{r(j+1)}^{p}$ and it can be represented in the following way,

$$
\begin{aligned}
& \text { So, if } \eta_{r j}^{p} \leq \eta_{r(j+1)}^{p}, y_{r j}^{p}=\left\{\begin{array}{cc}
0, & \text { if } \bar{x}_{r j}^{p} \geq W_{r j}^{\text {thres }} \\
W_{r j}^{\text {thres }}-\bar{x}_{r j}, & \text { if } \bar{x}_{r j}^{p}<W_{r j}^{\text {thres }}
\end{array},\right. \\
& \text { Hence, } z_{r j}^{p}= \begin{cases}0, & \bar{x}_{r j}^{p} \geq W_{r j}^{\text {thres }} \\
1, & \bar{x}_{r j}^{p}<W_{r j}^{\text {thres }}\end{cases}
\end{aligned}
$$

Where $W_{r j}^{\text {thres }}$ is the threshold limit up to which the fuel can be bunkered at $j^{\text {th }}$ port of call of route $r \in R$.

Proof. The proposition is easily proved by considering assumption 1 related to the amount of fuel bunkered on the vessel depending upon the remaining fuel on the vessel. (Zhen et al., 2017) discussed about the threshold based policy in their research and stated that when the available fuel on the vessel after arriving at $j^{\text {th }}$ port of call, is less than a certain threshold limit $\left(\right.$ or, $\left.x_{r j}<W_{r j}^{\text {thres }}\right)$, then the bunkering is performed at the $j^{\text {th }}$ port of call $\left(\right.$ or, $\left.z_{r j}^{p}=1\right)$, and the bunkering amount at $j^{\text {th }}$ port of call is given by $y_{r j}^{p}=W_{r j}^{t h r e s}-\bar{x}_{r j}^{p}$. Moreover, fuel bunkering takes place after comparing the fuel price at the current port with the next port.

\section{Solution methodology}

In this section, we propose an approximate algorithm based on the mathematical formulation and taking into account fuel bunkering policies. The computation of the mixed integer non-linear programming model is challenging, and it becomes even more complex with consideration of different fuel bunkering policies along with the mathematical model. Several authors have developed 
robust algorithms for solving mixed integer non-linear programming model due to the difficulty in solving such complex problems ((Krasko et al., 2017) and (Boukouvala et al., 2016)). Moreover, with the increasing number of routes, port of calls and bunker price scenarios, the number of decision variables for the mathematical model increases. Therefore, solving such a complex problem is computationally challenging, time-consuming and needs tremendous memory requirements (De et al., 2017). Such complex problems require intelligent search heuristics or random heuristics (De et al., 2019a). Therefore, we propose an approximate algorithm for solving the bunker fuel management problem, and it comprises of four algorithms.

Algorithm (1) provided in appendix A presents the procedure for computing the sailing speed and fuel consumption for different sailing legs. Algorithm (2) aims to determine the number of vessels deployed on a sailing route. Algorithm (3) estimates the arrival time and departure time of all the vessels deployed on the sailing route. Finally, algorithm (4) helps in determining the bunkering ports and bunkering amounts for all the vessels while considering the proposed fuel bunkering policies given in section 4. The vessel speed range for different ship sizes is taken into consideration for determining the sailing speed of the vessel on different legs for every route. For different fuel price scenarios, the fuel consumption of each sailing leg of the route has been estimated by applying equation (10).

The integer variable associated with the number of vessels assigned to each of the route for every fuel price scenario is determined using the equation (12). Time spent by a vessel at a port $t_{r j}^{\text {port }}$ is computed by considering the predetermined interval $\left[\overline{t_{r j}^{\text {port }}}, t_{r j}^{\text {port }}\right]$. Let $t_{r j p}^{\text {total }}$ be the total time required by the vessel to perform its service at the port and sail from one port to another.

Proposition 4. As $t_{r j p}^{\text {total }}$ is the total time spent by the vessel at $j^{\text {th }}$ port and the time taken on the sailing leg starting from $j^{\text {th }}$ port of route $r \in R$ under certain fuel price scenario $p \in P$, hence, $t_{r j p}^{\text {total }}$ can be determined using the following conditions,

$t_{r j p}^{\text {total }}=\left\{\begin{array}{c}t_{r j}^{\text {port }}, \quad \text { if } j=P_{r} \\ t_{r j}^{\text {port }}+\frac{D_{r j}}{s_{r j}^{p}}, \text { if } j \neq P_{r}\end{array}\right.$,

where $P_{r}^{\text {th }}$ port is the last port associated with route $r \in R$

Proof. The proof is quite straightforward. For the first port of call of route $r \in R, t_{r 1 p}^{\text {total }}$ (where $j=1$ ) is the time spent by the vessel in performing its port operations at the first port of call and the time required in sailing from first port of call to the second port of call and it can be 
represented as $t_{r 1 p}^{\text {total }}=t_{r 1}^{\text {port }}+\frac{D_{r 1}}{S_{r 1}}$. Similarly, for other port of calls, the total time spent by the vessel can be computed accordingly. Although once the vessel reaches its last port of call or $P_{r}^{\text {th }}$ port, then $t_{r P_{r} p}^{\text {total }}=t_{r P_{r}}^{\text {port }}+\frac{D_{r P_{r}}}{s_{r P_{r}}}=t_{r P_{r}}^{p o r t}$, as $\frac{D_{r P_{r}}}{s_{r P_{r}}}=0$ or the vessel ends its voyage at $P_{r}^{\text {th }}$ port, hence there is no sailing from $P_{r}^{\text {th }}$ port to any other port. Hence, this completes the proof.

Algorithm (2) provided in appendix A presents the procedure for determining the value of the integer variable $n_{r}^{p}$. Equation (29) pertaining to $t_{r j p}^{\text {total }}$ and equation (12) related to the sailing time and service time are used in the procedure illustrated in algorithm (2). Let $t_{r p}^{\text {route }}$ be the total time taken by a vessel on route $r \in R$ under scenario $p \in P$ and $t_{r p}^{\text {route }}$ can be depicted from equation (12). Hence, $t_{r p}^{\text {route }}$ is given by,

$t_{r p}^{\text {route }}=\sum_{j \in \lambda_{r}}\left(\frac{D_{r j}}{-p}+t_{r j}^{\text {port }} s_{r j}\right) \quad \forall r \in R, \forall p \in P$

As the number of vessels deployed on a route is an integer variable, hence $n_{r}^{p}$ can be computed in the following way,

$$
n_{r}^{p}=\left\lceil\frac{t_{r p}^{\text {route }}}{168}\right\rceil \quad \forall r \in R, \forall p \in P
$$

In equation (31), number of vessels assigned to a route is equal to the least integer number greater than or equal to $\left(t_{r p}^{\text {route }} / 168\right)$.

Appendix A provides the pseudo-code of algorithm (3) which aims to determine the arrival time and departure time of the vessels deployed on the sailing route. The starting time of the operation for a vessel at its initial port position (or the starting port) is assumed beforehand. So, the arrival time of the vessel at its initial port position is equal to the starting time of operation for the vessel. Departure time of the vessel at its initial port can be computed using the following equation,

$$
t_{r j p}^{d e p}=t_{r j}^{p o r t}+t_{r j p}^{a r r} ; \quad \forall r \in R, \forall j \in \lambda_{r}, \forall p \in P
$$

The travel time of the vessel on the sailing leg starting from $j^{\text {th }}$ port of call of route $r \in R$ is given by $t_{r j p}^{\text {travel }}$ and it can be computed in the following way, 


$$
t_{r j p}^{\text {travel }}=\frac{D_{r j}}{s_{r j}} ; \quad \forall r \in R, \forall j \in \lambda_{r}
$$

From the second port of calls onwards, the arrival time of the vessel can be determined using the departure time from the last port of call and travelling time between the two subsequent ports. Suppose, Arrival_time is equal to the remainder of $t_{r j p}^{a r r} / 24$, then, the departure time for the vessels can be computed in the following way, $t_{r j p}^{d e p}=\left\{\begin{array}{l}t_{r j p}^{a r r}+\underline{\mu_{r j}}-\text { Arrival_time }+t_{r j}^{p o r t}, \text { if Arrival_time }<\underline{\mu_{r j}} \\ t_{r j}^{\text {port }}+t_{r j p}^{a r r}, \text { if Arrival_time } \geq \underline{\mu_{r j}}\end{array}\right.$

An example is presented over here to describe the working procedure of equation (34). Suppose, $t_{r j p}^{\text {arr }}=124$ hours, for $j=5$, therefore Arrival_time $=$ remainder of $t_{r j p}^{\text {arr }} / 24=4$ hours. Moreover, the time window window range is given as $\mu_{r j}=6$ and $\overline{\mu_{r j}}=18$ and the service time of the vessel at the $j^{\text {th }}$ port of call is given as $t_{r j}^{\text {port }}=10$ hours. Therefore, equation (34) can be used for determining the value of the departure time for the vessel at the $j^{\text {th }}$ port of call (here, $j=5$ ). Now, as Arrival_time $<\mu_{r j}$, therefore the departure time of the vessel, $t_{r j p}^{d e p}$ is determined using the following equation:

$$
t_{r j p}^{d e p}=t_{r j p}^{a r r}+\underline{\mu_{r j}}-\text { Arrival_time }+t_{r j}^{p o r t} . \text { Using the data, } t_{r j p}^{d e p}=124+6-4+10=136
$$

hours. So, the departure time of the vessel at the $j^{t h}$ port of call is $t_{r j p}^{d e p}=136$ hours. The detailed procedure of the generation of arrival time and departure time variables is given in algorithm (3).

Algorithm (4) provides the detailed procedure for determining the values of the bunkering variables such as bunker fuel while arriving at the port, bunker fuel while leaving the port, total amount of fuel bunkered at the port and binary variable depicting whether bunkering takes place or not.

The step wise procedure of the algorithm 4 (provided in Appendix A) depicting the estimation of the bunkering variables are as follows,

Step 1: For the initial port position of the vessel, the value of the variable depicting the bunker fuel inventory while arriving at the port is equivalent to the maximum bunker fuel capacity of the vessel. As Max_HFO is the maximum bunkering capacity of the vessel, hence $\bar{x}_{r j}=$ Max_HFO. Moreover, bunkering doesn't takes place at the initial port, hence the bunker fuel inventory while leaving the initial port for the vessel is 
equal to the bunker fuel inventory while arriving at the initial port or $\underline{x}_{r j}^{p}=\bar{x}_{r j}$. Assuming, End_fuel $=\underline{x}_{r j}^{p}$ and fuel consumed while sailing from the initial port to next port of call is given by, Travel_fuel $=G_{r j}^{\max }\left(\bar{s}_{r j}\right)$.

Step 2: From the second port of call of the vessel to third last port of call, the bunkering of fuel will be performed on the basis of certain strategies. At first, the bunker fuel inventory after arriving at port can be computed in the following way $\bar{x}_{r j}=$ End_fuel-Travel_fuel. Now, comparing the bunker fuel prices on the current port and next port of call of the vessel and considering the amount of bunker fuel inventory available on the vessel after arriving at the port, the following bunkering decisions are taken into account - 1) whether to perform bunkering at the current port, 2) amount of fuel bunkered at the port (if bunkering of fuel is performed) and 3) bunker fuel inventory of the vessel while leaving the port.

Step 2.1: Suppose the bunker fuel price at the current port is greater than the fuel price at the next port visit of the vessel (or, $\eta_{r j}^{p} \geq \eta_{r(j+1)}^{p}$ ) and the bunker fuel inventory while arriving at the port is less than the fuel required to travel from the current port to the next port of call for the vessel (or, $x_{r j}<G_{r j}^{\max }\left(s_{r j}^{p}\right)$ ). Under this circumstances, the fuel bunkering is performed at the current port (or $z_{r j}^{p}=1$ ). Bunkered amount can be computed in the following way, $y_{r j}^{p}=G_{r j}^{\max }\left(\bar{s}_{r j}^{p}\right)-\bar{x}_{r j}^{p}$ and bunker fuel inventory while leaving the port is the summation of fuel inventory of the vessel while arriving at the port and amount of fuel bunkered (or, $\underline{x}_{r j}^{p}=y_{r j}^{p}+\bar{x}_{r j}^{p}$ ).

Step 2.2: When the bunker fuel price at the current port is greater than that of the next port of call of the vessel (or, $\eta_{r j}^{p} \geq \eta_{r(j+1)}^{p}$ ) and fuel inventory of the vessel while arriving at the port is greater than the fuel required for sailing from the current port to the next port (or, $\bar{x}_{r j} \geq G_{r j}^{\max }\left(\bar{s}_{r j}\right)$ ), then no bunkering takes place at the current port (or, $z_{r j}^{p}=0$ ). Hence, bunkered amount is equivalent to zero (or, $y_{r j}^{p}=0$ ) and bunker fuel inventory of the vessel while leaving the port is same as that of the fuel inventory while arriving at the port (or, $\underline{x}_{r j}^{p}=\bar{x}_{r j}^{p}$ ).

Step 2.3: Suppose the bunker fuel price at the current port of call of the vessel is less than fuel price at the next port visit of the vessel (or, $\eta_{r j}^{p}<\eta_{r(j+1)}^{p}$ ) and bunker fuel inventory on the vessel after arriving at the current port is less than a certain threshold level (or, $\bar{x}_{r j}^{p}<W_{r j}^{t h r e s}$ ). In such a scenario, the bunkering of fuel is performed (or, $z_{r j}^{p}=1$ ) and 
bunker amount can be computed in the following way, $y_{r j}^{p}=W_{r j}^{t h r e s}-\bar{x}_{r j}^{p}$. The bunker fuel inventory of the vessel while leaving the port is given as follows, $\underline{x}_{r j}^{p}=y_{r j}^{p}+x_{r j}$.

Step 2.4: When the fuel price at the current port of the vessel is less than the fuel price at the next port visit of the vessel (or, $\eta_{r j}^{p}<\eta_{r(j+1)}^{p}$ ) and the fuel inventory of the vessel after arriving at the port is greater than the threshold limit (or, $\bar{x}_{r j}^{p} \geq W_{r j}^{\text {thres }}$ ), then no bunkering of fuel takes place at the current port (or $z_{r j}^{p}=0$ and $y_{r j}^{p}=0$ ). Moreover, vessel's fuel inventory while leaving the port is same as that of its fuel inventory while arriving at the port (or, $\underline{x}_{r j}^{p}=\bar{x}_{r j}^{p}$ ).

End_fuel and Travel_fuel get updated at the end of step 2.

Step 3: For the second last port of call of the vessel, the bunker fuel inventory of the vessel can be estimated in the following way, $\bar{x}_{r j}^{p}=$ End_fuel-Travel_fuel. If the bunker fuel inventory of the vessel while arriving at the port is greater than the fuel required to sail from the second last port of call of the vessel to the last port of call (or, $\left.\bar{x}_{r j}^{p} \geq G_{r j}^{\max }\left(s_{r j}\right)\right)$, then no fuel bunkering is performed at the second last port visit of the vessel (or, $z_{r j}^{p}=0$ and $y_{r j}^{p}=0$ ) and bunker fuel inventory while leaving the second last port of call is given in the following way, $\underline{x}_{r j}^{p}=\bar{x}_{r j}^{p}$. Although, if the vessel's fuel inventory while arriving at the second last port visit is less than the fuel required for sailing the last leg of the route (or, $x_{r j}^{p}<G_{r j}^{\max }\left(s_{r j}^{p}\right)$ ), then the fuel bunkering is carried out at the second last port of the call of the vessel (or, $z_{r j}^{p}=1$ ). The bunkered amount can be computed in the following way, $y_{r j}^{p}=G_{r j}^{\max }\left(s_{r j}\right)-\bar{x}_{r j}$ and vessel's fuel inventory while leaving the second last port of call is given as, $\underline{x}_{r j}^{p}=y_{r j}^{p}+\bar{x}_{r j}^{p}$. End_fuel and Travel_fuel gets updated at the end of step 3

Step 4: For the last port of call of the vessel, the bunker fuel inventory while arriving at the port is computed in the following way, $\bar{x}_{r j}^{p}=$ End_fuel-Travel_fuel. Fuel inventory while leaving the port is given by, $\underline{x}_{r j}^{p}=\bar{x}_{r j}^{p}$ and other bunkering decisions are given as $z_{r j}^{p}=0$ and $y_{r j}^{p}=0$.

\section{Computational Experiment}

This section presents the computational experiments based on the Asia-Europe-Oceania network of a global liner shipping network. Wang et al., (2015) provided the data related to different 
vessel types, namely 3000 TEU, $5000 \mathrm{TEU}$, and $8000 \mathrm{TEU}$. The 3000 TEU type is considered to incur a weekly cost of USD 100,000 and a bunker tank capacity of 50,000 tons. The bunker consumption of the $3000 \mathrm{TEU}$ type is given by the following equation, $B_{r j}(s)=0.01 s^{3}$ where, $a_{r j}=0.01$ and $b_{r j}=3$. For the $5000 \mathrm{TEU}$ and $8000 \mathrm{TEU}$ types, the weekly operating cost is considered to be USD 150,000 and USD 200,000, respectively, with bunker tank capacity of 80,000 tons and 100,000 tons, respectively. The bunker consumption of the 5000 TEU type is given as $B_{r j}(s)=0.004 s^{3.3}$, where $a_{r j}=0.004$ and $b_{r j}=3.3$. For the 8000 TEU type, the bunker

consumption equation can be expressed as $B_{r j}(s)=0.04 s^{2.7}$, where $a_{r j}=0.04$ and $b_{r j}=2.7$. Bunker consumption equations for different vessels types are elaborately presented in Wang et al., (2015). The Asia-Europe-Oceania shipping network consists of 46 ports, 3 types of vessels (3000 TEU, 5000 TEU and 8000 TEU) and 11 vessel routes. Table 1 presents the various ship routes navigated by three types of vessels. The maximum vessel speed associated with the 3000 TEU, 5000 TEU, and 8000 TEU vessel types are 23 knots, 26 knots, and 28 knots, respectively. Bunker fuel prices lie within the range of 300-500 USD per ton and four bunkering pricing scenarios are considered, with their respective probabilities given as $0.2,0.3,0.1$, and 0.4 . Unit inventory cost $\alpha$ expressed in USD per ton per hour is considered as 0.5 and the vessel speed variability represented as $s^{\text {err }}$ is assumed as 3 . The majority of the data considered in resolving the mathematical model are borrowed from Wang et al., (2015), De et al., (2016,2017), and Zhen et al., (2017). Penalty costs associated with delays in finishing port operations and penalty charges for waiting time before the start of the time-window are generated within a range of 100-500 USD per hour.

The range of the number of containers transported on a sailing leg by vessel type are generated as follows: 3000 TEU type (2000-3000); 5000 TEU type (4000-5000); and 8000 TEU (7000-8000). Time spent by a vessel at a port is considered to fluctuate within a range of $7-10$ hours. The start and end time of the time window are generated to be within the range of 6-10 hours and 16-20 hours, respectively. The computational experiments were performed on MATLAB R2015b software with 8GB RAM with Intel Core i7 1.8 GHz processor and a 64-bit Windows 7 operating system.

\subsection{Analysis of Results}

The results of the Asia-Europe-Oceania global liner shipping network are presented in table 2. The table shows the cost components for the overall inventory carried, the bunkering of heavy fuel oil, and fuel consumption at ports. The table also mentions the fixed operating cost related to the number of vessels hired for weekly service on each route. This also includes penalty cost for waiting time before the start of the time-window and delay in finishing port operations. It is observed that majority of the cost largely comprises of bunkering cost related to the heavy fuel oil. Table 3 presents 
the results pertaining to the first fuel price scenario and also the number of vessels required on different vessel routes. Vessel speed, fuel consumption and travelling time on different sailing legs of each route are also mentioned in the table. Three vessels of type $5000 \mathrm{TEU}$ are required to operate on the first route. The vessel speed on sailing legs associated with Singapore to Brisbane, Brisbane to Sydney, Sydney to Melbourne, Melbourne to Adelaide and Adelaide to Fremantle are 23, 25, 17, 15 and 24 knots respectively. Fuel consumption (in tons) and travelling time (in hour) related to the five sailing legs of the first route are 22170.6 - 3566.5 - 1760.2 - 1200.8 - 8504.5 tons and 3842 - 515 $582-514-1343$ hours respectively. For completing the overall voyage, the number of vessels required in $1^{\text {st }}, 2^{\text {nd }}, 8^{\text {th }}, 9^{\text {th }}$ and $11^{\text {th }}$ ship routes are three, five, two, two and six respectively.

It is observed that the majority of the cost is attributable to the cost of bunkering heavy fuel oil. Table 3 presents the results pertaining to the first fuel price scenario and also the number of vessels required for different vessel routes. Vessel speed, fuel consumption and travelling time on different sailing legs of each route are also mentioned in this table. Three vessels of 5000 TEU type are required to operate on the first route. Each sailing leg and its vessel speed are broken down as follows: Singapore to Brisbane (23 knots); Brisbane to Sydney (25 knots); Sydney to Melbourne (17 knots); Melbourne to Adelaide (15 knots); and Adelaide to Fremantle (24 knots). Fuel consumption (in tons) for the five sailing legs of the first route are: Singapore to Brisbane (22170.6); Brisbane to Sydney (3566.5); Sydney to Melbourne (1760.2); Melbourne to Adelaide (1200.8); and Adelaide to Fremantle (8504.5). Meanwhile, travelling time (in hours) for each leg is as follows: Singapore to Brisbane (3842); Brisbane to Sydney (515); Sydney to Melbourne (582); Melbourne to Adelaide (514); and Adelaide to Fremantle (1343).

A single vessel performing the service of visiting all ports and transporting containers between various sailing legs is considered here. Table 4 provides the values related to the arrival and departure time of the vessel at different ports of call for shipping route 11. Figure 1 presents the visual illustration of the trade route for the shipping route 11 and provides information pertaining to the bunkering ports. Time window range is relaxed while conducting this experiment of a single vessel travelling to all ports. The vessel takes around 43 days to complete the overall voyage. The fuel inventory while arriving and departing from a ports are also presented in this table. Bunkering decisions are determined taking into consideration the values of the bunker fuel price at each port and the amount of fuel inventory available on the vessel while arriving at each port. The vessel performs fuel bunkering seven times at different ports including Colombo, Singapore, Hong Kong, and Shanghai. As fuel bunkering policies are determined based on the fuel prices at different ports, most of the time bunkering is performed at ports where the bunker fuel price is lowest. Bunker fuel price at the same port changes at different periods of time due to the variability associated with fuel price. The bunkered amounts of fuel at each bunkering port are presented in table 4. This experiment helps to 
identify the impact of fuel bunkering policy when it comes to determining bunkering ports and bunkering amount while keeping in mind the fluctuating fuel prices at different ports.

Table 1: Port of calls for each route along with the distance of the sailing legs

\begin{tabular}{|c|c|c|c|}
\hline $\begin{array}{l}\text { Ship } \\
\text { route No. }\end{array}$ & Ship type & Port of calls & $\begin{array}{l}\text { Distance of the sailing legs } \\
\text { (nautical miles) }\end{array}$ \\
\hline 1 & $5000 \mathrm{TEU}$ & $\begin{array}{c}\text { Singapore } \rightarrow \text { Brisbane } \rightarrow \text { Sydney } \rightarrow \text { Melbourne } \rightarrow \text { Adelaide } \rightarrow \\
\text { Fremantle }\end{array}$ & $3842-515-582-514-1343$ \\
\hline 2 & $5000 \mathrm{TEU}$ & $\begin{array}{l}\text { Xiamen } \rightarrow \text { Chiwan } \rightarrow \text { Hong Kong } \rightarrow \text { Singapore } \rightarrow \text { Port Klang } \\
\quad \rightarrow \text { Salalah } \rightarrow \text { Jeddah } \rightarrow \text { Aqabah } \rightarrow \text { Salalah } \rightarrow \text { Singapore }\end{array}$ & $\begin{array}{c}341-20-1460-210-2998-1351 \\
-569-1985-3177 \\
\end{array}$ \\
\hline 3 & $3000 \mathrm{TEU}$ & Yokohama $\rightarrow$ Tokyo $\rightarrow$ Nagoya $\rightarrow$ Kobe $\rightarrow$ Shanghai & $18-226-245-783$ \\
\hline 4 & $3000 \mathrm{TEU}$ & Ho Chi Minh $\rightarrow$ Laem Chabang $\rightarrow$ Singapore $\rightarrow$ Port Klang & $634-784-210$ \\
\hline 5 & $3000 \mathrm{TEU}$ & $\begin{array}{c}\text { Brisbane } \rightarrow \text { Sydney } \rightarrow \text { Melbourne } \rightarrow \text { Adelaide } \rightarrow \text { Fremantle } \rightarrow \\
\text { Jakarta } \rightarrow \text { Singapore }\end{array}$ & $515-582-514-1343-1763-525$ \\
\hline 6 & $3000 \mathrm{TEU}$ & $\begin{array}{c}\text { Manila } \rightarrow \text { Kaohsiung } \rightarrow \text { Xiamen } \rightarrow \text { Hong Kong } \rightarrow \text { Yantian } \rightarrow \\
\text { Chiwan } \rightarrow \text { Hong Kong }\end{array}$ & $543-164-287-30-43-20$ \\
\hline 7 & $3000 \mathrm{TEU}$ & $\begin{array}{c}\text { Dalian } \rightarrow \text { Xingang } \rightarrow \text { Qingdao } \rightarrow \text { Shanghai } \rightarrow \text { Ningbo } \rightarrow \text { Shanghai } \rightarrow \text { Kwangyang } \rightarrow \text { Busan } \\
\text { Sw }\end{array}$ & $\begin{array}{c}214-418-352-91-117-435- \\
101\end{array}$ \\
\hline 8 & $3000 \mathrm{TEU}$ & $\begin{aligned} \text { Chittagong } & \rightarrow \text { Chennai } \rightarrow \text { Colombo } \rightarrow \text { Cochin } \rightarrow \text { Nhava Sheva } \\
& \rightarrow \text { Cochin } \rightarrow \text { Colombo } \rightarrow \text { Chennai }\end{aligned}$ & $\begin{array}{c}891-590-307-583-606-259- \\
615 \\
\end{array}$ \\
\hline 9 & $5000 \mathrm{TEU}$ & $\begin{aligned} \text { Sokhna } \rightarrow \text { Aqabah } & \rightarrow \text { Jeddah } \rightarrow \text { Salalah } \rightarrow \text { Karachi } \rightarrow \text { Jebel Ali } \\
& \rightarrow \text { Salalah }\end{aligned}$ & $245-573-1372-1027-746-999$ \\
\hline 10 & $8000 \mathrm{TEU}$ & $\begin{array}{c}\text { Southampton } \rightarrow \text { Thamesport } \rightarrow \text { Hamburg } \rightarrow \text { Bremerhaven } \rightarrow \\
\text { Rotterdam } \rightarrow \text { Antwerp } \rightarrow \text { Zeebrugge } \rightarrow \text { Le Havre }\end{array}$ & $\begin{array}{c}154-531-120-263-71-52- \\
208\end{array}$ \\
\hline 11 & $8000 \mathrm{TEU}$ & $\begin{array}{c}\text { Southampton } \rightarrow \text { Sokhna } \rightarrow \text { Salalah } \rightarrow \text { Colombo } \rightarrow \text { Singapore } \rightarrow \\
\text { Hong Kong } \rightarrow \text { Xiamen } \rightarrow \text { Shanghai } \rightarrow \text { Busan } \rightarrow \text { Dalian } \rightarrow \\
\text { Xingang } \rightarrow \text { Qingdao } \rightarrow \text { S } \\
\text { Shanghai } \rightarrow \text { Hong Kong } \rightarrow \text { Singapore } \rightarrow \text { Colombo } \rightarrow \text { Salalah }\end{array}$ & $\begin{array}{c}3272-1880-1640-1602-1463- \\
294-587-476-450-214-418- \\
352-820-1455-1597-1632\end{array}$ \\
\hline
\end{tabular}

Table 2: Results associated with all the cost components for all the scenarios and overall expected cost

\begin{tabular}{|c|c|c|c|c|c|c|}
\hline Scenario & $\begin{array}{c}\text { Total inventory } \\
\text { cost (USD) }\end{array}$ & $\begin{array}{c}\text { Bunker cost for } \\
\text { heavy fuel oil } \\
\text { (USD) }\end{array}$ & $\begin{array}{c}\text { Fuel consumption } \\
\text { cost at port (USD) }\end{array}$ & $\begin{array}{c}\text { Fixed } \\
\text { operating } \\
\text { cost (USD) }\end{array}$ & $\begin{array}{c}\text { Penalty } \\
\text { charges for } \\
\text { waiting }\end{array}$ & $\begin{array}{c}\text { Penalty } \\
\text { charges for } \\
\text { delaying }\end{array}$ \\
\hline 1 & $7.305 \times 10^{6}$ & $4.240 \times 10^{7}$ & $6.568 \times 10^{2}$ & $7.6 \times 10^{5}$ & $3.277 \times 10^{4}$ & $2.249 \times 10^{4}$ \\
\hline 2 & $7.584 \times 10^{6}$ & $3.501 \times 10^{7}$ & $1.022 \times 10^{3}$ & $1.2 \times 10^{6}$ & $4.981 \times 10^{4}$ & $2.127 \times 10^{4}$ \\
\hline 3 & $7.459 \times 10^{6}$ & $4.671 \times 10^{7}$ & $3.249 \times 10^{2}$ & $4.1 \times 10^{5}$ & $2.703 \times 10^{4}$ & $2.329 \times 10^{4}$ \\
\hline 4 & $7.539 \times 10^{6}$ & $3.284 \times 10^{7}$ & $1.325 \times 10^{3}$ & $1.52 \times 10^{6}$ & $2.774 \times 10^{4}$ & $2.255 \times 10^{4}$ \\
\hline $\begin{array}{c}\text { Total } \\
\text { expected cost }\end{array}$ & $7.497 \times 10^{6}$ & $3.679 \times 10^{7}$ & $1.001 \times 10^{3}$ & $1.161 \times 10^{6}$ & $3.530 \times 10^{4}$ & $2.223 \times 10^{4}$ \\
\hline
\end{tabular}


Table 3: Results pertaining to the number of vessels for each route and vessel speed, fuel consumption and travelling time on every sailing leg

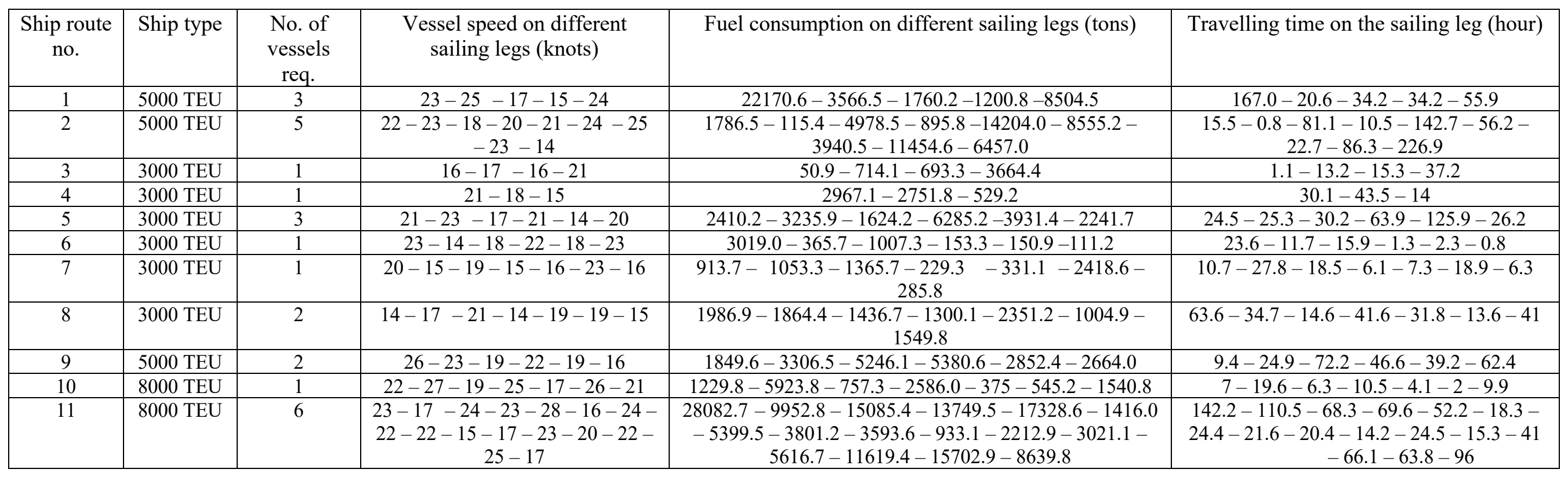


Table 4: Results pertaining to the ship route 11 for scenario 1

\begin{tabular}{|c|c|c|c|c|c|c|c|c|c|}
\hline Port of calls & $\begin{array}{c}\text { Arrival } \\
\text { day }\end{array}$ & $\begin{array}{l}\text { Arrival time } \\
\text { (hours) }\end{array}$ & $\begin{array}{c}\text { Departure } \\
\text { day }\end{array}$ & $\begin{array}{c}\text { Departure } \\
\text { time (hours) }\end{array}$ & $\begin{array}{c}\text { Fuel inventory } \\
\text { while arriving at } \\
\text { the port (tons) }\end{array}$ & $\begin{array}{c}\text { Bunkering } \\
\text { ports }\end{array}$ & $\begin{array}{c}\text { Bunker fuel } \\
\text { price } \\
\text { (USD/ton) }\end{array}$ & $\begin{array}{c}\text { Bunkered } \\
\text { amounts (tons) }\end{array}$ & $\begin{array}{c}\text { Fuel inventory while } \\
\text { departing from the } \\
\text { port (tons) }\end{array}$ \\
\hline Southampton & 1 & 10 & 1 & 18 & $1.00 \times 10^{5}$ & - & 397 & - & $1.00 \times 10^{5}$ \\
\hline Sokhna & 7 & 16.2 & 8 & 1.2 & $7.191 \times 10^{4}$ & - & 458 & - & $7.191 \times 10^{4}$ \\
\hline Salalah & 12 & 15.8 & 12 & 23.8 & $6.196 \times 10^{4}$ & - & 376 & - & $6.196 \times 10^{4}$ \\
\hline Colombo & 15 & 20.1 & 16 & 3.1 & $4.687 \times 10^{4}$ & Colombo & 370 & $3.312 \times 10^{4}$ & $8.00 \times 10^{4}$ \\
\hline Singapore & 19 & 0.8 & 19 & 16 & $6.625 \times 10^{4}$ & - & 443 & - & $6.625 \times 10^{4}$ \\
\hline Hong Kong & 21 & 20.2 & 22 & 5.2 & $4.892 \times 10^{4}$ & Hong Kong & 334 & $3.107 \times 10^{4}$ & $8.00 \times 10^{4}$ \\
\hline Xiamen & 22 & 23.6 & 23 & 8.6 & $7.858 \times 10^{4}$ & Xiamen & 335 & $1.416 \times 10^{3}$ & $8.00 \times 10^{4}$ \\
\hline Shanghai & 24 & 9.1 & 24 & 16.1 & $7.460 \times 10^{4}$ & Shanghai & 353 & $5.399 \times 10^{3}$ & $8.00 \times 10^{4}$ \\
\hline Busan & 25 & 13.7 & 25 & 22.7 & $7.619 \times 10^{4}$ & - & 497 & - & $7.619 \times 10^{4}$ \\
\hline Dalian & 26 & 19.1 & 27 & 3.2 & $7.260 \times 10^{4}$ & Dalian & 318 & $7.394 \times 10^{3}$ & $8.00 \times 10^{4}$ \\
\hline Xingang & 27 & 17.4 & 28 & 0.4 & $7.906 \times 10^{4}$ & - & 472 & - & $7.906 \times 10^{4}$ \\
\hline Qingdao & 29 & 1.0 & 29 & 16 & $7.685 \times 10^{4}$ & - & 377 & - & $7.685 \times 10^{4}$ \\
\hline Shanghai & 30 & 7.3 & 30 & 17 & $7.383 \times 10^{4}$ & Shanghai & 354 & $6.167 \times 10^{3}$ & $8.00 \times 10^{4}$ \\
\hline Hong Kong & 32 & 10 & 32 & 18 & $7.438 \times 10^{4}$ & - & 457 & - & $7.438 \times 10^{4}$ \\
\hline Singapore & 35 & 12.1 & 35 & 21.1 & $6.276 \times 10^{4}$ & Singapore & 342 & $1.723 \times 10^{4}$ & $8.00 \times 10^{4}$ \\
\hline Colombo & 38 & 13.01 & 38 & 23.01 & $6.429 \times 10^{4}$ & - & 498 & - & $6.429 \times 10^{4}$ \\
\hline Salalah & 42 & 23 & 43 & 9 & $5.565 \times 10^{4}$ & - & 388 & - & $5.565 \times 10^{4}$ \\
\hline
\end{tabular}




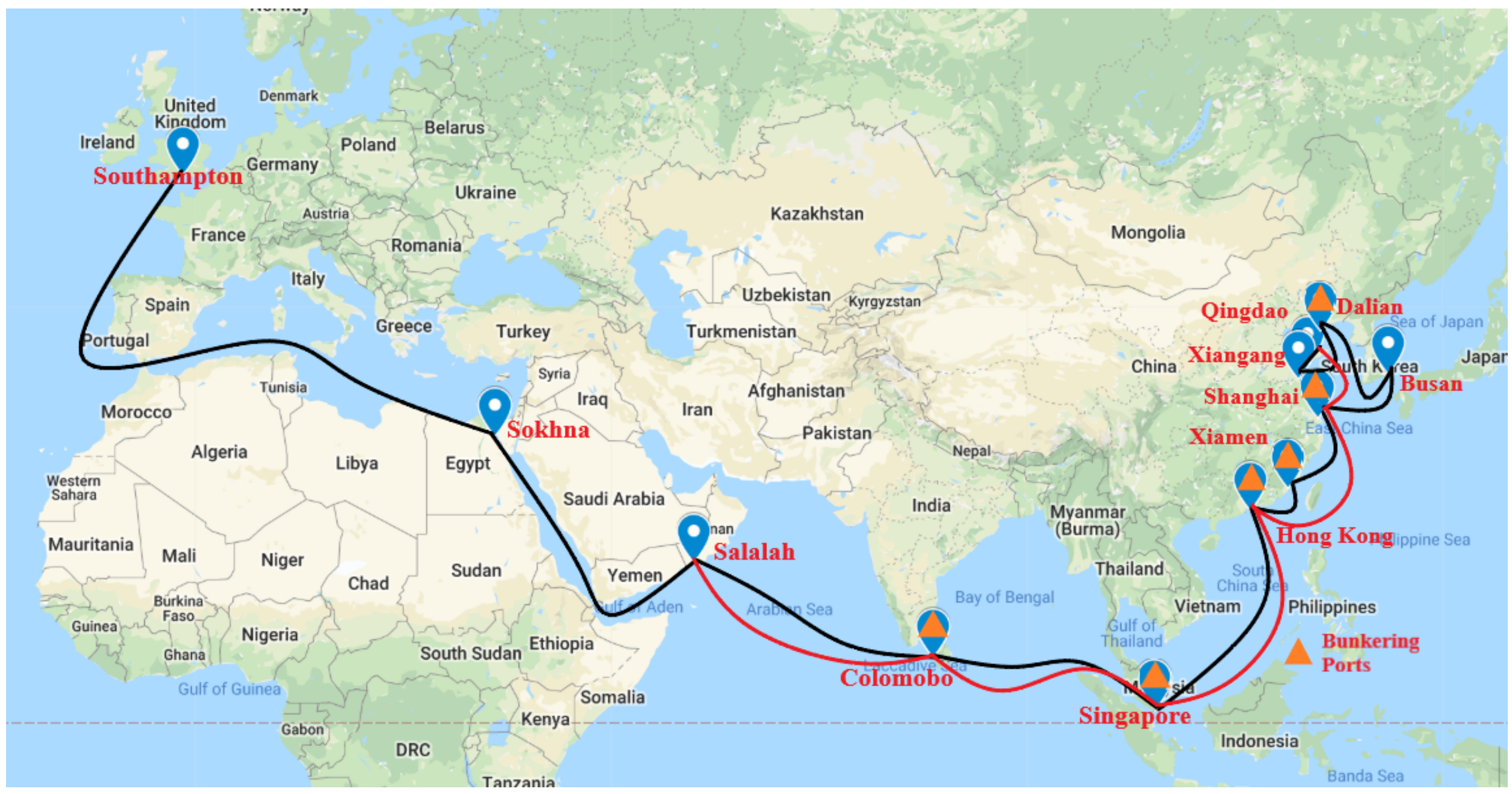

Figure 1: Trade route for the ship route 11 


\subsection{Atlantic Pacific Express (APX) Service Route}

We consider the APX service route, which contains 24 ports of call, to study the effect of bunker fuel prices on bunker fuel management strategy. A vessel of 5000 TEU type operating on the service route is considered for this study. The number of vessels required to perform the weekly service needs to be determined. Bunker consumption of a 5000 TEU type vessel is $B_{r j}(s)=0.004 s^{3.3}$ as mentioned in Wang \& Meng, 2015, where $a_{r j}=0.004$ and $b_{r j}=3.3$. A single scenario of bunker fuel prices for different ports is considered for the APX service route. Table 5 provides fuel prices at various ports. Bunkering is performed at various ports such as Miami, Jacksonville, Savannah, Rotterdam, Felixstowe, Norfolk, Charleston and Oakland with their bunker fuel prices (USD/ton) as $321,439,476,400,401,308,336$ and 318 respectively. The bunkering amounts at Miami, Rotterdam, Norfolk and Oakland are $1.796 \times 10^{4}, 3.020 \times 10^{4}, 2.395 \times 10^{4}$ and $3.042 \times 10^{4}$ tons of fuel respectively. The average fuel price, taking into consideration all of the ports on this route is $392.25 \mathrm{USD} /$ ton. However, the fuel prices at the bunkering ports of Miami, Rotterdam, Norfolk and Oakland, are 321, 400, 308 and $318 \mathrm{USD} /$ ton respectively. It is noted that the fuel prices at Miami, Norfolk and Oakland are much lower than the average fuel price. Figure 2 presents the trade route of the APX service route and provides information on the locations of the bunkering ports.

The effect of fluctuating bunker fuel prices are examined by considering the following seven scenarios: 1) fuel prices for heavy fuel oil at each port remains unchanged; 2) fuel prices are increased by $10 \%$; 3) fuel prices are increased by $20 \%$, 4) fuel prices are increased by $30 \%$; 5) fuel prices are decreased by $10 \%$; 6) fuel prices are decreased by $20 \%$; and 7) fuel prices are decreased by $30 \%$. For a fair comparison, the speed variability for each of the cases are considered as 2 , or $s^{\text {err }}=2$ and data associated with all seven scenarios remains unchanged. Table 6 presents the total cost and bunker cost for all seven scenarios. It can be interpreted that the total cost increases by $8.07 \%, 16.14 \%$ and $24.22 \%$ for the $10 \%, 20 \%$ and $30 \%$ increases in the bunker fuel prices respectively. The share of the bunker cost within the total cost for all seven scenarios is $80.77 \%$ in the first scenario, $82.20 \%$ in the second scenario, $83.44 \%$ in the third scenario, $84.49 \%$ in the fourth scenario, $79.04 \%$ in the fifth scenario, $77.03 \%$ in the sixth scenario, and $74.58 \%$ in the seventh scenario. It is inferred that with the increase in bunker fuel prices at different ports, the percentage share of the bunker cost on the total cost increases. Similarly, with the decrease in fuel prices at different ports, the bunker cost share decreases. Therefore, it is suggested that that bunker fuel prices at different ports are directly proportional to the percentage share of bunker cost.

\subsection{Managerial Implications}

Liner shipping companies are generally concerned about reaching ports at the pre-agreed time (i.e. neither early nor late) and are therefore prone to increasing the fuel consumption cost. 
Nevertheless, addressing the bunker fuel management problem by considering slow steaming and taking into account suitable fuel bunkering policies presented in this paper will help such shipping companies to reduce their overall fuel consumption cost. As bunkering cost represents a significant part of the total cost of a shipping company, it is paramount to investigate the incorporation of a slow steaming strategy to reduce fuel consumption as well as the adoption of fuel bunkering policies to lower the bunkering cost.

It has been observed that the main tendency of a vessel to perform its bunkering at ports where the fuel price is low is to reduce its overall bunkering cost. The bunkering port selection for a vessel are affected by the fuel prices along the service route, which, in turn, have a significant impact on the overall bunkering cost. The bunkering policies presented in this paper will help the shipping companies to determine the bunkering ports for their vessels based on the respective fuel prices at each port. The shipping company compares the fuel prices at two subsequent ports of call and decides at which port it should perform bunkering and the amount of fuel to be bunkered. Moreover, the shipping company also estimates the maximum amount of fuel consumed by a vessel while sailing between two ports of call and, accordingly, makes bunkering decisions according to the amount of fuel to be bunkered based on the fuel price at the port. In addition, it is imperative to predict the maximum fuel consumption for a vessel on various sailing legs as this helps to determine the potential bunkering ports and bunkering amounts based on fuel prices. The effect of changing bunker fuel prices provides us with an idea about the percentage share of the bunkering cost within the total cost, as mentioned in table 6 . As the majority of the cost incurred for a shipping company largely comprises the bunkering cost, it is therefore essential to adopt appropriate fuel bunkering policies to reduce bunkering cost, which, in turn, minimizes the total cost. The total cost might be higher for shipping companies that opt against sustainable approaches like a slow steaming strategy and/or fuel bunkering policy.

\section{Conclusions}

Our research addresses the problem of bunker fuel management for a liner shipping network under different fuel pricing scenarios. A mixed integer non-linear programming model is presented to determine the total expected cost comprising inventory cost, bunkering cost, fuel consumption cost, and penalty cost for waiting time before starting port operations and penalty charges for violating the pre-agreed time window. It is observed that vessels of liner shipping companies aim to reach their ports of call early to meet the demand in a timely manner and that, in the process of doing so, they compromise with their fuel consumption. The rise of fuel consumption increases their fuel cost, but this can be lowered by adopting various fuel bunkering policies and strategically bunkering at ports where fuel prices are lower. The practical aspects of fluctuating fuel prices at different ports have been considered while validating the adopted fuel bunkering policies. A heuristic has been proposed by considering the structure of the mathematical formulation and different fuel bunkering policies. 
The proposed heuristic is used to perform computational experiments on the Asia-Europe-Oceania network and the APX service routes. From our study of the effects of bunker fuel prices, we have derived valuable insights for the decision makers.

This research can be extended by addressing the increasing concerns about environmental issues in international shipping, specifically in terms of reducing the emission of greenhouse gases from vessels. Moreover, uncertainties associated with the disruptive aspects of maritime transportation need to be dealt with. Such disruption could include weather-related adversities within specific sailing legs, port closure due to poor weather conditions, and labour strikes. Recently, several powerful decomposition techniques have emerged to solve this complicated problem by decomposing the problem into several sub-problems. A multi-objective optimization problem could be developed, taking into consideration the time-varying stochastic price-dependent demand (Ghoreishi et al., (2015)) and robust algorithms can be developed as solution methodologies (Kara et al., (2019), Pervin et al., (2018), Roy et al., (2017), and Özöugür et al., (2016)). Moreover, machine learning algorithms (Alkahtani, et al., (2019) including regression methodologies ((Taylan et al., 2019b) and (Taylan et al., 2019a)), artificial neural networks and support vector machines ((Erdogan et al., 2019), (Savku et al., (2014) and Savku et al., (2018)), modern optimization techniques (Alp et al., (2011)) and environmentally conscious optimization (Paksoy et al., 2014) can be used for predicting the fuel pricing scenarios and bunker fuel prices at different port of calls based on the historical data. In future, this research could also be extended by using weather data to estimate the real-time fuel consumption which may differ depending upon the weather conditions in the voyage.

\section{Acknowledgement}

We thank both the Editor and the reviewers for their constructive comments and contributions to enhance the quality, clarity and presentation of our research. This research has been made available through the European Union Europe Aid-funded Project "EU-India Research \& Innovation Partnership for Efficient and Sustainable Freight Transportation (REINVEST)," Contract Number: $\mathrm{R} / 141842$. The contents of this publication are the sole responsibility of the authors of this paper and can in no way be taken to reflect the views of the European Union. 
Table 5: Results associated with Atlantic Pacific Express (APX) service route

\begin{tabular}{|c|c|c|c|c|c|c|c|c|}
\hline Sailing legs of the route & $\begin{array}{c}\text { Distance between } \\
\text { two ports (nautical } \\
\text { miles) }\end{array}$ & $\begin{array}{l}\text { Vessel } \\
\text { speed } \\
\text { (knots) }\end{array}$ & $\begin{array}{c}\text { Fuel } \\
\text { consumption } \\
\text { (tons) }\end{array}$ & $\begin{array}{c}\text { Bunker fuel price } \\
\text { at each port } \\
\text { (USD/ton) }\end{array}$ & $\begin{array}{l}\text { Fuel inventory } \\
\text { while arriving at } \\
\text { the port (tons) }\end{array}$ & $\begin{array}{c}\text { Bunkering } \\
\text { ports }\end{array}$ & $\begin{array}{c}\text { Bunkered } \\
\text { amounts (tons) }\end{array}$ & $\begin{array}{c}\text { Fuel inventory } \\
\text { while departing } \\
\text { from the port (tons) }\end{array}$ \\
\hline Chiwan $\rightarrow$ Hong Kong & 20 & 20 & 85.32 & Chiwan -362 & $8.00 \times 10^{4}$ & - & - & $8.00 \times 10^{4}$ \\
\hline Hong Kong $\rightarrow$ Kaohsiung & 355 & 18 & 1210.53 & Hong Kong -369 & $7.991 \times 10^{4}$ & - & - & $7.991 \times 10^{4}$ \\
\hline Kaohsiung $\rightarrow$ Busan & 976 & 18 & 3328.12 & Kaohsiung -398 & $7.870 \times 10^{4}$ & - & - & $7.870 \times 10^{4}$ \\
\hline Busan $\rightarrow$ Kobe & 366 & 25 & 2534.66 & Busan - 469 & $7.537 \times 10^{4}$ & - & - & $7.537 \times 10^{4}$ \\
\hline Kobe $\rightarrow$ Tokyo & 356 & 19 & 1361.23 & Kobe -321 & $7.284 \times 10^{4}$ & - & - & $7.284 \times 10^{4}$ \\
\hline Tokyo $\rightarrow$ Balboa & 7710 & 16 & 20560.74 & Tokyo -413 & $7.148 \times 10^{4}$ & - & - & $7.148 \times 10^{4}$ \\
\hline Balboa $\rightarrow$ Manzanillo & 39 & 15 & 91.11 & Balboa - 351 & $5.091 \times 10^{4}$ & - & - & $5.091 \times 10^{4}$ \\
\hline Manzanillo $\rightarrow$ Miami & 1254 & 19 & 4794.92 & Manzanillo - 324 & $5.082 \times 10^{4}$ & - & - & $5.082 \times 10^{4}$ \\
\hline Miami $\rightarrow$ Jacksonville & 309 & 18 & 1053.67 & Miami -321 & $4.603 \times 10^{4}$ & Miami & $1.796 \times 10^{4}$ & $6.40 \times 10^{4}$ \\
\hline Jacksonville $\rightarrow$ Savannah & 123 & 24 & 778.89 & Jacksonville -439 & $6.294 \times 10^{4}$ & Jacksonville & $1.053 \times 10^{3}$ & $6.40 \times 10^{4}$ \\
\hline Savannah $\rightarrow$ Charleston & 109 & 17 & 329.66 & Savannah -476 & $6.322 \times 10^{4}$ & Savannah & $7.788 \times 10^{2}$ & $6.40 \times 10^{4}$ \\
\hline Charleston $\rightarrow$ New York & 636 & 24 & 4027.47 & Charleston -496 & $6.367 \times 10^{4}$ & - & - & $6.367 \times 10^{4}$ \\
\hline New York $\rightarrow$ Rotterdam & 3424 & 26 & 25849.24 & New York -488 & $5.964 \times 10^{4}$ & - & - & $5.964 \times 10^{4}$ \\
\hline Rotterdam $\rightarrow$ Bremerhaven & 245 & 14 & 497.94 & Rotterdam - 400 & $3.379 \times 10^{4}$ & Rotterdam & $3.020 \times 10^{4}$ & $6.40 \times 10^{4}$ \\
\hline Bremerhaven $\rightarrow$ Felixstowe & 327 & 22 & 1713.21 & Bremerhaven -415 & $6.350 \times 10^{4}$ & - & - & $6.350 \times 10^{4}$ \\
\hline Felixstowe $\rightarrow$ New York & 3374 & 25 & 23366.04 & Felixstowe -401 & $6.178 \times 10^{4}$ & Felixstowe & $2.211 \times 10^{3}$ & $6.40 \times 10^{4}$ \\
\hline New York $\rightarrow$ Norfolk & 289 & 14 & 587.37 & New York -490 & $4.063 \times 10^{4}$ & - & - & $4.063 \times 10^{4}$ \\
\hline Norfolk $\rightarrow$ Charleston & 433 & 15 & 1011.60 & Norfolk - 308 & $4.004 \times 10^{4}$ & Norfolk & $2.395 \times 10^{4}$ & $6.40 \times 10^{4}$ \\
\hline Charleston $\rightarrow$ Manzanillo & 1573 & 23 & 9077.15 & Charleston -336 & $6.298 \times 10^{4}$ & Charleston & $1.011 \times 10^{3}$ & $6.40 \times 10^{4}$ \\
\hline Manzanillo $\rightarrow$ San Pedro & 2290 & 24 & 18934.20 & Manzanillo - 431 & $5.492 \times 10^{4}$ & - & - & $5.492 \times 10^{4}$ \\
\hline San Pedro $\rightarrow$ Oakland & 381 & 24 & 2412.68 & San Pedro - 338 & $3.598 \times 10^{4}$ & - & - & $3.598 \times 10^{4}$ \\
\hline Oakland $\rightarrow$ Tokyo & 4557 & 18 & 15539.22 & Oakland -318 & $3.357 \times 10^{4}$ & Oakland & $3.042 \times 10^{4}$ & $6.40 \times 10^{4}$ \\
\hline Tokyo $\rightarrow$ Kobe & 362 & 18 & 1234.40 & Tokyo - 389 & $4.846 \times 10^{4}$ & - & - & $4.846 \times 10^{4}$ \\
\hline- & & & & Kobe -361 & $4.722 \times 10^{4}$ & - & - & $4.722 \times 10^{4}$ \\
\hline
\end{tabular}




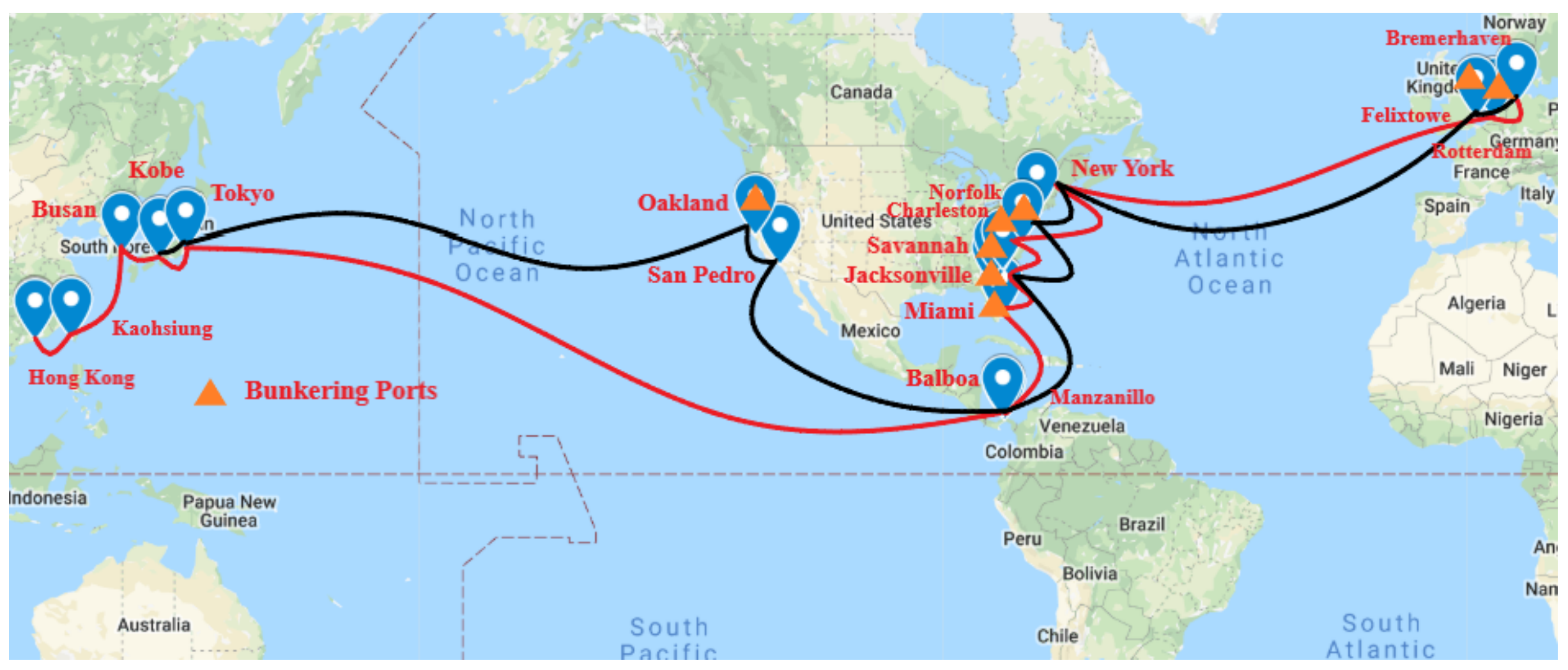

Figure 2: Trade route for the Atlantic Pacific Express service route 
Table 6: Effects of fuel prices on total cost and bunker cost

\begin{tabular}{|c|c|c|c|c|c|c|c|}
\hline Bunker Fuel Price & $\begin{array}{c}\text { Remains } \\
\text { unchanged }\end{array}$ & $\begin{array}{c}10 \% \\
\text { increase }\end{array}$ & $\begin{array}{c}20 \% \\
\text { increase }\end{array}$ & $\begin{array}{c}30 \% \\
\text { increase }\end{array}$ & $\begin{array}{c}10 \% \\
\text { decrease }\end{array}$ & $\begin{array}{c}20 \% \\
\text { decrease }\end{array}$ & $\begin{array}{c}30 \% \\
\text { decrease }\end{array}$ \\
\hline Total cost (USD) & $2.907 \times 10^{7}$ & $3.142 \times 10^{7}$ & $3.377 \times 10^{7}$ & $3.612 \times 10^{7}$ & $2.673 \times 10^{7}$ & $2.438 \times 10^{7}$ & $2.203 \times 10^{7}$ \\
\hline $\begin{array}{c}\% \text { change in the } \\
\text { total cost }\end{array}$ & - & $\begin{array}{c}8.07 \% \\
\text { increase }\end{array}$ & $\begin{array}{c}16.14 \% \\
\text { increase }\end{array}$ & $\begin{array}{c}24.22 \% \\
\text { increase }\end{array}$ & $\begin{array}{c}8.07 \% \\
\text { decrease }\end{array}$ & $\begin{array}{c}16.14 \% \\
\text { decrease }\end{array}$ & $\begin{array}{c}24.22 \% \\
\text { decrease }\end{array}$ \\
\hline Bunker Cost (USD) & $2.348 \times 10^{7}$ & $2.583 \times 10^{7}$ & $2.818 \times 10^{7}$ & $3.052 \times 10^{7}$ & $2.113 \times 10^{7}$ & $1.878 \times 10^{7}$ & $1.643 \times 10^{7}$ \\
\hline $\begin{array}{c}\% \text { share on bunker } \\
\text { cost on total cost }\end{array}$ & $80.77 \%$ & $82.20 \%$ & $83.44 \%$ & $84.49 \%$ & $79.04 \%$ & $77.03 \%$ & $74.58 \%$ \\
\hline
\end{tabular}

\section{References}

Agra, A., Christiansen, M., \& Delgado, A. (2013). Mixed integer formulations for a short sea fuel oil distribution problem. Transportation Science, 47(1), 108-124.

Alkahtani, M., Choudhary, A., De, A., \& Harding, J. A. (2019). A decision support system based on ontology and data mining to improve design using warranty data. Computers and Industrial Engineering, 128. https://doi.org/10.1016/j.cie.2018.04.033

Alp, Ö. S., Büyükbebeci, E., İşcanog, A., Özkurt, F. Y., Taylan, P., \& Weber, G.-W. (2011). CMARS and GAM \& CQP- modern optimization methods applied to international credit default prediction. Journal of Computational and Applied Mathematics, 235(16), 4639-4651.

Aydin, N., Lee, H., \& Mansouri, S. A. (2017). Speed optimization and bunkering in liner shipping in the presence of uncertain service times and time windows at ports. European Journal of Operational Research, 259(1), 143-154.

Boukouvala, F., Misener, R., \& Floudas, C. A. (2016). Global optimization advances in mixed-integer nonlinear programming, MINLP, and constrained derivative-free optimization, CDFO. European Journal of Operational Research, 252(3), 701-727.

De, A., Choudhary, A., \& Tiwari, M. K. (2017). Multiobjective Approach for Sustainable Ship Routing and Scheduling With Draft Restrictions. IEEE Transactions on Engineering Management. https://doi.org/10.1109/TEM.2017.2766443

De, A., Kumar, S. K., Gunasekaran, A., \& Tiwari, M. K. (2017). Sustainable maritime inventory routing problem with time window constraints. Engineering Applications of Artificial Intelligence, 61, 77-95.

De, A., Mamanduru, V. K. R., Gunasekaran, A., Subramanian, N., \& Tiwari, M. K. (2016). Composite particle algorithm for sustainable integrated dynamic ship routing and scheduling optimization. Computers \& Industrial Engineering, 96, 201-215.

De, A., Pratap, S., Kumar, A., \& Tiwari, M. K. (2018). A hybrid dynamic berth allocation planning problem with fuel costs considerations for container terminal port using chemical reaction optimization approach. Annals of Operations Research, 1-29.

De, A., Wang, J., \& Tiwari, M. K. (2019a). Hybridizing Basic Variable Neighborhood Search With Particle Swarm Optimization for Solving Sustainable Ship Routing and Bunker Management Problem. IEEE Transactions on Intelligent Transportation Systems.

De, A., Wang, J., \& Tiwari, M. K. (2019b). Fuel Bunker Management Strategies Within Sustainable Container Shipping Operation Considering Disruption and Recovery Policies. IEEE Transactions on Engineering Management. DOI: 10.1109/TEM.2019.2923342

Erdogan, B. E., Özöugür-Akyüz, S., \& Ataş, P. K. (2019). A novel approach for panel data: An ensemble of weighted functional margin SVM models. Information Sciences.

Fagerholt, K., Laporte, G., \& Norstad, I. (2010). Reducing fuel emissions by optimizing speed on shipping routes. Journal of the Operational Research Society, 61(3), 523-529.

Ghoreishi, M., Weber, G.-W., \& Mirzazadeh, A. (2015). An inventory model for non-instantaneous 
deteriorating items with partial backlogging, permissible delay in payments, inflation-and selling price-dependent demand and customer returns. Annals of Operations Research, 226(1), 221238.

Ghosh, S., Lee, L. H., \& Ng, S. H. (2015). Bunkering decisions for a shipping liner in an uncertain environment with service contract. European Journal of Operational Research, 244(3), 792802.

Hemmati, A., Hvattum, L. M., Christiansen, M., \& Laporte, G. (2016). An iterative two-phase hybrid matheuristic for a multi-product short sea inventory-routing problem. European Journal of Operational Research, 252(3), 775-788.

Hvattum, L. M., Norstad, I., Fagerholt, K., \& Laporte, G. (2013). Analysis of an exact algorithm for the vessel speed optimization problem. Networks, 62(2), 132-135.

Kara, G., Özmen, A., \& Weber, G.-W. (2019). Stability advances in robust portfolio optimization under parallelepiped uncertainty. Central European Journal of Operations Research, 27(1), 241-261.

Kim, H.-J., Chang, Y.-T., Kim, K.-T., \& Kim, H.-J. (2012). An epsilon-optimal algorithm considering greenhouse gas emissions for the management of a ships bunker fuel. Transportation Research Part D: Transport and Environment, 17(2), 97-103.

Kim, H. J. (2014). A Lagrangian heuristic for determining the speed and bunkering port of a ship. Journal of the Operational Research Society, 65(5), 747-754.

Krasko, V., \& Rebennack, S. (2017). Two-stage stochastic mixed-integer nonlinear programming model for post-wildfire debris flow hazard management: Mitigation and emergency evacuation. European Journal of Operational Research, 263(1), 265-282.

Meng, Q., Wang, S., \& Lee, C.-Y. (2015). A tailored branch-and-price approach for a joint tramp ship routing and bunkering problem. Transportation Research Part B: Methodological, 72, 1-19.

Notteboom, T. E., \& Vernimmen, B. (2009). The effect of high fuel costs on liner service configuration in container shipping. Journal of Transport Geography, 17(5), 325-337.

Özöugür Akyüz, S., Üstünkar, G., \& Weber, G.-W. (2016). Adapted infinite kernel learning by multilocal algorithm. International Journal of Pattern Recognition and Artificial Intelligence, 30(04), 1651004.

Paksoy, T., \& Özceylan, E. (2014). Environmentally conscious optimization of supply chain networks. Journal of the Operational Research Society, 65(6), 855-872.

Pervin, M., Roy, S. K., \& Weber, G.-W. (2018). Analysis of inventory control model with shortage under time-dependent demand and time-varying holding cost including stochastic deterioration. Annals of Operations Research, 260(1-2), 437-460.

Ronen, D. (2011). The effect of oil price on containership speed and fleet size. Journal of the Operational Research Society, 62(1), 211-216.

Roy, S. K., Maity, G., Weber, G.-W., \& Gök, S. Z. A. (2017). Conic scalarization approach to solve multi-choice multi-objective transportation problem with interval goal. Annals of Operations Research, 253(1), 599-620.

Savku, E., Azevedo, N., \& Weber, G.-W. (2014). Optimal Control of Stochastic Hybrid Models in the Framework of Regime Switches. In International Conference on Dynamics, Games and Science (pp. 371-387).

Savku, E., \& Weber, G.-W. (2018). A stochastic maximum principle for a markov regime-switching jump-diffusion model with delay and an application to finance. Journal of Optimization Theory and Applications, 1-26.

Sheng, X., Lee, L. H., \& Chew, E. P. (2014). Dynamic determination of vessel speed and selection of bunkering ports for liner shipping under stochastic environment. OR Spectrum, 36(2), 455-480.

Taylan, P., \& Weber, G.-W. (2019a). C-LASSO Estimator for Generalized Additive Logistic 
Regression Based on B-Spline. In Data Science and Digital Business (pp. 173-190). Springer.

Taylan, P., \& Weber, G.-W. (2019b). CG-Lasso Estimator for Multivariate Adaptive Regression Spline. In Mathematical Methods in Engineering (pp. 121-136). Springer.

Vernimmen, B., Dullaert, W., \& Engelen, S. (2007). Schedule unreliability in liner shipping: Origins and consequences for the hinterland supply chain. Maritime Economics \& Logistics, 9(3), 193213.

Wang, S. (2016). Fundamental properties and pseudo-polynomial-time algorithm for network containership sailing speed optimization. European Journal of Operational Research, 250(1), $46-55$.

Wang, S., \& Meng, Q. (2012a). Liner ship route schedule design with sea contingency time and port time uncertainty. Transportation Research Part B: Methodological, 46(5), 615-633.

Wang, S., \& Meng, Q. (2012b). Sailing speed optimization for container ships in a liner shipping network. Transportation Research Part E: Logistics and Transportation Review, 48(3), 701714.

Wang, S., \& Meng, Q. (2015). Robust bunker management for liner shipping networks. European Journal of Operational Research, 243(3), 789-797.

Wang, S., \& Wang, X. (2016). A polynomial-time algorithm for sailing speed optimization with containership resource sharing. Transportation Research Part B: Methodological, 93, 394-405.

Yao, Z., Ng, S. H., \& Lee, L. H. (2012). A study on bunker fuel management for the shipping liner services. Computers \& Operations Research, 39(5), 1160-1172.

Zhen, L., Wang, S., \& Zhuge, D. (2017). Dynamic programming for optimal ship refueling decision. Transportation Research Part E: Logistics and Transportation Review, 100, 63-74. 


\section{Supplementary material}

\section{Appendix A}

Algorithm 1: Generation of vessel speed variable and fuel consumption function Procedure: Generation of vessel speed variable $\bar{s}_{r j}^{p}$ and bunker fuel consumption value $G_{r j}^{\max }\left(\overrightarrow{s_{r j}}\right)$

1. for $p=1$ to number of fuel price scenarios

2. for $r=1$ to number of sailing routes

3. $A=$ Total number of port of calls on route $r$

4. for $j=1$ to number of port of calls for route $r$

5. if $j=A$

6. $\quad s_{r j}^{-p}=0, G_{r j}^{\max }\left(s_{r j}^{-p}\right)=0$

7. else

8. $\quad \bar{s}_{r j}=$ Random integer within specific range

9. $G_{r j}^{\max }\left(\bar{s}_{r j}^{p}\right)=\frac{a_{r j} D_{r j}}{2 s_{r j}}\left[\left(\bar{s}_{r j}^{p}+s^{e r r}\right)^{b_{r j}}+\left(\bar{s}_{r j}^{p}-s^{e r r}\right)^{b_{r j}}\right]$

10. end

11. end

12. end

13. end

Algorithm 2: Determining the number of vessels deployed on a route

Procedure: Generation of integer variable $n_{r}^{p}$

1. time $=0$

2. for $p=1$ to number of fuel price scenarios

3. for $r=1$ to number of sailing routes

4. $A=$ Total number of port of calls on route $r$

5. for $j=1$ to number of port of calls for route $r$

6. $\quad$ if $j=A$

7. $\quad t_{r j p}^{\text {total }}=t_{r j}^{\text {port }}$

8. $\quad$ else

9. $\quad t_{r j p}^{\text {total }}=t_{r j}^{\text {port }}+\left(D_{r j} / 4 t_{r j}^{c o n}\right)$

10. end

11. $\quad$ time $=t_{\text {rjp }}^{\text {total }}+$ time

12. end

13. $\quad t_{r p}^{\text {route }}=$ time, $n_{r}^{p}=\left\lceil t_{r p}^{\text {route }} / 168\right\rceil$

14. time $=0$

15. end

16. end 
Algorithm 3: Estimation of arrival time and departure time related decision variables

Procedure: Generation of arrival time $\left(t_{r j p}^{\text {arr }}\right)$ variable and departure time $\left(t_{r j p}^{\text {dep }}\right)$ variable 1. Start_time $=$ Start time of operation at the initial port of a vessel

2. for $p=1$ to number of fuel price scenarios

3. for $r=1$ to number of sailing routes

4. $\quad A=$ Total number of port of calls on route $r$

5. for $j=1$ to number of port of calls for route $r$

6. $\quad$ if $j=1$

7. $\quad$ Assign the value of Start_time to $t_{r j p}^{a r r}, t_{r j p}^{a r r}=$ Start_time

8. $\quad$ Compute $t_{r j p}^{d e p}$ using the equation, $t_{r j p}^{d e p}=t_{r j p}^{a r r}+t_{r j}^{\text {port }}$

9. $\quad$ Assign the value of $t_{r j p}^{\text {dep }}$ to Depart_time, or Depart_time $=t_{\text {rjp }}^{d e p}$

10. $\quad$ Compute $t_{r j p}^{\text {travel }}$ using the equation, $t_{r j p}^{\text {travel }}=D_{r j} / \bar{s}_{r j}^{p}$

11. Assign the value of $t_{\text {rjp }}^{\text {travel }}$ to Travel_time, or Travel_time $=t_{\text {rjp }}^{\text {travel }}$

12. end

13. if $j>1$

14. $\quad$ Estimate the value of $t_{r j p}^{a r r}$ using, $t_{r j p}^{a r r}=$ Depart_time + Travel_time

15. Assign the value of Arrival_time as the remainder of $\left(t_{r j p}^{\text {arr }} / 24\right)$

16. $\quad$ if Arrival_time $<\mu_{r j}$

17. Compute $t_{r j p}^{\text {dep }}$ using the equation, $t_{r j p}^{d e p}=t_{r j p}^{a r r}+\mu_{r j}-$ Arrival_time $+t_{r j}^{\text {port }}$ 18. else

19.

20.

21.

22.

23.

24.

25.

26.

27.

28.

Compute $t_{r j p}^{d e p}$ using the equation, $t_{r j p}^{d e p}=t_{r j p}^{a r r}+t_{r j}^{p o r t}$ end

Assign the value of $t_{r j p}^{d e p}$ to Depart_time, or Depart_time $=t_{r j p}^{d e p}$ if $j=A$

Assign the value of $t_{r j p}^{\text {travel }}$ as zero, or $t_{r j p}^{\text {travel }}=0$ else

Estimate the value of $t_{r j p}^{\text {travel }}$ using the equation, $t_{r j p}^{\text {travel }}=D_{r j} / s_{r j}^{-p}$ end

Assign the value of $t_{r j p}^{\text {travel }}$ to Travel_time, or Travel_time $=t_{r j p}^{\text {travel }}$

29. end

30. end

31. end 


\section{Algorithm 4: Estimation of fuel bunkering related decision variables}

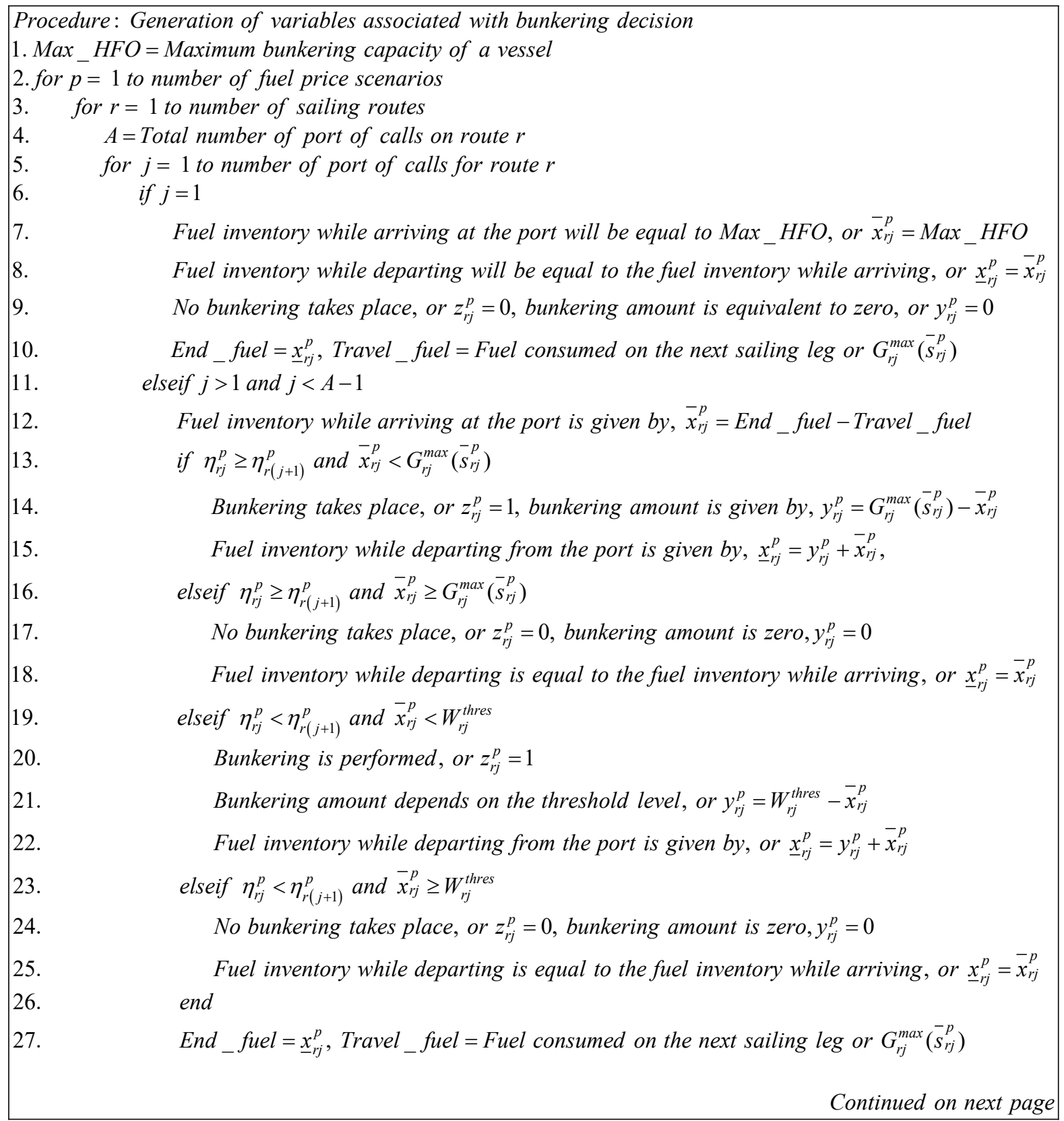


28.

29.

30.

31.

32.

33.

34.

35.

36.

37.

38.

39.

40.

41.

42.

43.

44.

45. end

46. end

elseif $j=A-1$

Fuel inventory while arriving at the port is given by, $\bar{x}_{r j}^{p}=$ End_fuel-Travel_fuel if $\bar{x}_{r j} \geq G_{r j}^{\max }\left(\bar{s}_{r j}\right)$

No bunkering takes place, or $z_{r j}^{p}=0$, bunkering amount is zero, $y_{r j}^{p}=0$

Fuel inventory while departing is equal to the fuel inventory while arriving, or $\underline{x}_{r j}^{p}=\bar{x}_{r j}^{p}$ elseif $\bar{x}_{r j}^{p}<G_{r j}^{\max }\left(\bar{s}_{r j}^{p}\right)$

Bunkering takes place, or $z_{r j}^{p}=1$, bunkering amount is given by, $y_{r j}^{p}=G_{r j}^{\max }\left(\bar{s}_{r j}^{p}\right)-\bar{x}_{r j}^{p}$

Fuel inventory while departing from the port is given $b y, \underline{x}_{r j}^{p}=y_{r j}^{p}+\bar{x}_{r j}^{p}$ end

End_fuel $=\underline{x}_{r j}^{p}$, Travel_fuel $=$ Fuel consumed on the next sailing leg or $G_{r j}^{\max }\left(\bar{s}_{r j}^{p}\right)$ elseif $j=A$

Fuel inventory while arriving at the port is given by, $\bar{x}_{r j}=$ End_fuel-Travel_fuel

No bunkering takes place at the final port of call, or $z_{r j}^{p}=0$

Bunkering amount is zero at the final port of call, $y_{r j}^{p}=0$

Fuel inventory while departing is equal to the fuel inventory while arriving, or $\underline{x}_{r j}^{p}=\bar{x}_{r j}^{p}$ end

end

end 
